\title{
Adding Resilience To Financial Markets: Toward a Volatility-based, Power-Law Indicated, Resilience Initiation Point
}

\author{
Rossitsa Yalamova \\ University of Lethbridge, Faculty of Management, Lethbridge, AB T1K 3M4 \\ Phone 0044-58 666 4474; Fax 403-329-2038; rossitsa.yalamova@uleth.ca \\ $\&$
}

Bill McKelvey

UCLAAnderson School of Management, 110 Westwood Plaza, Los Angeles, CA 90095-1481

Phone 310-825-7796; Fax 310-206-2002; mckelvey@anderson.ucla.edu

(c) Copyright. All rights reserved. Not to be quoted, paraphrased, copied, or distributed in any fashion without permission.

September 2010 
Classic financial economics dates back to three dominant Finance paradigms, the efficient market hypothesis (EMH; Fama, 1970), the capital-asset pricing model (CAPM; Sharpe, 1964; Lintner, 1965; Black, 1972), and the Black-Scholes (1973) options-pricing model. The Economist (2009b: 70) observes that we now know that the 25-year "Great Moderation" period has ended, in which macro- and financial economists blithely presumed that their independent, identically distributed (i.i.d.), normal-distribution assumptions of efficient-market trader and asset-pricing behaviors and consequent theoretical and quantitative models offered inevitably correct views of real-world market behavior.

With the failure of LTCM (Long-Term Capital Management) in 1998, Nobel Laureates Myron Scholes and Robert Merton learned the hard way about the limitations of "value-at-risk" (VAR) models. As The Economist observes, VAR models are:

...Used by institutional investors to work out how much capital they need to set aside as insurance against losses on risky assets. These models mistakenly assume that the volatility of asset prices and the correlations between prices are constant, says Mr. Scholes. When, say, two types of asset were assumed to be uncorrelated, investors felt able to hold the same capital as a cushion against losses on both, because they would not lose on both at the same time. (2009a: 71)

The Economist continues by observing that the LTCM debacle and the 2007 liquidity crisis both demonstrate just how quickly supposedly "uncorrelated" asset-price movements can become highly correlated, leading all traders toward the same buy/sell motivations, which then leads to a market crash. ${ }^{1}$

But hardly a new concern. At the time that Louis Bachelier invented the random walk (in his PhD dissertation of 1900; book in 1914) to describe price fluctuations on the Paris Bourse (stock exchange), his dissertation advisor, Henri Poincaré is famous for imposing caution in reviewing the dissertation at the time; later saying:

When men are brought together they no longer decide by chance and independently of each other, but react upon one another. Many causes come into action, they trouble the men and draw them this way and that, but there is one thing they cannot destroy, the habits they have of Panurge's sheep $(1914, \text { p. } \sim 88)^{2}$

As Mandelbrot has noted for decades, we see transitions from efficient markets to correlated trader behaviors and bubble-build-ups to market crashes far more often than expected: "'Modern' financial theory is founded on a few, shaky myths that lead us to underestimate the real risk of financial markets' and: 'Orthodox financial theory is riddled with false assumptions and wrong results' (Mandelbrot \& Hudson, 2004, pp. ix, x). Cooper (2008, p. 11) says: 'Despite overwhelming evidence to the contrary, the Efficient Market Hypothesis remains the bedrock of how conventional wisdom views the financial system...' According to Fama (1998), however, until new and better paradigm is put forth, one cannot criticize EMH/CAPM. Fama reduces

\footnotetext{
${ }^{1}$ The Economist even more strongly emphasizes its and others' concerns about VAR, correlated trading behaviors and price movements, as well as positive feedback in its 18 page Special report on financial risk [2010 (Feb 13); inserted between pp. 52 and 53].

${ }^{2}$ In the $16^{\text {th }}$ century French writer Rabelais' book, Gargantua and Pantagruel, Pantagruel's companion, Panurge, met a sheep dealer on a boat. Becoming upset after buying a sheep (which happened to be the alpha ram) at too high a price, Panurge threw it overboard - whereupon all the other sheep, crying and bleating, jumped overboard after it. Hence the expression, 'the sheep of Panurge' applied to people like stock traders who let themselves be led blindly by others without thinking.
} 
behavioral finance - and trading dynamics - to anomalies and over-/under-reaction episodes that are normally distributed.

The problem is how to find ways to keep financial market behaviors resilient against the kinds of correlated behaviors that lead to crashes. The Economist (2009a) reports Scholes as favoring independent capital reserves for each kind of asset so as to avoid unexpected crash-creating correlated asset-price movements. In our view, Scholes' suggestion is unnecessary if markets are still in efficient-market mode (Fama, 1970) — where greed, fear, and uncertainty are balanced (our "Triple Point") — and insufficient if correlated trading of highly leveraged financial products dominates. The 2007 liquidity crisis, bank failures, and consequent Great Recession remind us that it is still possible for unanticipated, sudden, correlated behaviors to spiral up into stock market bubbles which end in crashes - our "Critical Point."

For us, it is the tipping point between one kind of market behavior vs. the other that is important. We draw on basic Econophysics (West \& Deering, 1995; Mantegna \& Stanley, 2002; Vasconcelos, 2004), Hyman Minsky (1982, 1986), power-law science (Andriani \& McKelvey, 2007, 2009, 2010a), the Hurst exponent (Struzik, 2001; Grech \& Mazur, 2004; Cajueiro \& Tabak, 2004; Alvarez-Ramirez et al., 2008; Masakawa, 2007; Yalamova, 2003, 2010; ), and logperiodic power laws (Yan, Woodard \& Sornette, 2010) to identify the tipping point where efficient markets transform into crash-producing stock-market bubbles. This growing literature underlies our resilience-engineering approach for minimizing damage from inevitable extreme price volatilities and market crashes. This literature brings a set of new ideas and solutions into the world of financial markets.

Ideally one would like to create financial markets that are robust against meltdowns. Failing this, one should promulgate resilience as early acting as possible. To accomplish this, we draw on Minsky's "positive-feedback" theory about market bubbles and crashes $(1982,1986)$, and suggest several additional "scale-free" causes of skew distributions, that when combined lead to the extreme outcomes of long-tailed Pareto distributions, as signified by power laws (PLs) (Newman, 2005). We draw on Bak's (1996) "self-organized criticality" theory signify increasing PL distributions of price (stock return) volatilities in market trading as general indicators of impending crashes, as traders move away from an efficient-market's Triple Point toward the Critical Point (Yalamova \& McKelvey, 2009). We suggest $\sim 40$ formulaic resilience engineering interventions to be automatically imposed after the tipping point so as to thwart the market crash vulnerabilities of financial engineering

We begin with a short connection back to key elements seen as essential ingredients of resilient systems in general, as presented Hollnagel et al.'s book, Resilience Engineering (2006). Next, we give a brief introduction to econophysics, power laws, and scalability, which offer a different view of stock markets than does conventional wisdom stemming from Fama's efficient market perspective and Black-Scholes' options-pricing model. Then, in Sections III and IV we review various inventions and market behaviors between 1973 and 2008 to show how often herding, ${ }^{3}$ Minsky's "positive feedback," and various additional scale-free spirals become embedded in trader behaviors. These sections offer historical support for our application of the complexity-science perspective along with a direct linking of various phases of the build-up to

\footnotetext{
${ }^{3}$ Herding — when traders trend toward following the same trading approach (such as rule-based trading). In financial markets herding is well documented empirically (Banerjee, 1992; Bikhchandani, et al., 1992; Brunnermeier, 2001; Rook, 2006).
} 
the 2007 liquidity crisis to several scale-free theories - which explain shifts from Gaussian- to Pareto-distributed volatilities. In Section VI we use the 'volatility autocorrelation function', log periodicity, and the Hurst exponent to identify our ' $R 1$ ' tipping-point — which indicates when market price volatilities shift from efficient-market trading at the Triple Point to PL-indicated bubble-build-ups toward the Critical Point. Given evidence that trading volatilities exceed the $R 1$ tipping point, in Section VII we outline a range of suggested resilience-inducing behaviors that could be set off automatically or by regulators' actions. These include (1) required information disclosures, (2) interventions thwarting willful reckless endangerment, (3) interventions increasing insurance against market-failure consequences, (4) Glass-Steagall alternatives, and (5) resilience against the consequences of systemic interconnectivities. A conclusion follows.

\section{KEY ELEMENTS OF RESILIENCE ENGINEERING}

Before getting into details about the nature of financial-market phenomena and their amenability to resilience engineering, we briefly define some aspects of resilience engineering in general. We take as our point of departure some of the concepts and precepts developed in Resilience Engineering (Hollnagel et al., 2006). These consist of resilience typologies applied to top-down managed organizations, to systems that can't be allowed to fail, to totally unexpected disasters like the 9/11 disaster, and finally to disasters scaling up from "tiny initiating events" (TIEs) (Holland, 1995, 2002) via "circular causal dynamics."

\section{A. ORganizational RESILIENCE}

In their Prologue, Woods and Hollnagel (2006) begin by pointing out that disasters are usually the result of unexpected combinations of several events - there are usually, if not always multiple initiating events. They note that failures are often the results of production-schedule pressures - the Russians call this "Storming" (Andriani \& McKelvey, 2010b). Woods and Hollnagel observe that the "new approach" to safety is "proactive resilient processes," as opposed to simply learning about past mistakes (p. 3). They find that proactive behavior by employees works better than preconceived, rigid policies. People need to actively work toward creating failure minimizing strategies. They say:

Resilience engineering is a paradigm for safety management that focuses on how to help people cope with complexity under pressure to achieve success. It strongly contrasts with what is typical today - a paradigm of tabulating error as if it were a thing, followed by interventions to reduce this count. A resilient organization treats safety as a core value, not a commodity that can be counted.... One measure of resilience is therefore the ability to create foresight - to anticipate the changing shape of risk, before failure and harm occurs (Woods, 2005; our emphasis). (Quoted in Woods \& Hollnagel, 2006: 6).

Pariès (2006) says, " ...organizational resilience is an emerging property of complex systems" (p. 43). He separates phenomena into "nominal," "weakly," and "strongly emergent resilience" as follows (we alter terms somewhat):

1. Predictive (nominally) emergent resilience: The component elements of a system behave like pixels on one's monitor. Individually they make no sense at all; collectively they create everything we see and understand. Trying to predict the whole from the individually meaningless parts is useless. And yet we can see on our monitor, and find out in other complex systems, that collections of meaningless component elements often have macro meaning. Imagine all the parts of a mechanical clock piled up on a table-looks like a pile of junk. And yet, with proper design the macro construction is a totally predictable entity. 
2. Simple-rule-based (weakly) emergent resilience: There are no simple formulas that can create prediction from seeming randomness. Applies mostly to larger physical systems where the individual variations of the many small parts are annihilated by their interactions; individual variations become subject to statistical treatments such as via Boltzmann's statistical mechanics. In this case, random individual variations can combine to create identifiable macro behavior. For example, one random ant finds food and then unknowingly lays down a pheromone trail as it brings the prey back to the nest; other ants find the trail, follow it, find food, and return to the nest. A positive-feedback spiral develops. Yes, humans are smarter than ants, but we know of many cases where people show collective behavior emerging from individuals following simple rules (Epstein \& Axtell, 1996; Holland, 1998; Miller \& Page, 2007).

3. Recursive (strongly) emergent resilience: There are no apparent bases of macro behavior stemming from constituent agents' attributes or rule-based behaviors. Here we have "circular causal dynamics" (p. 53) that are set off by events outside a group of agents rather than by one or more of their own individual attitudes or rule-based behaviors. Thus, the "attractor" that sets off the recursive build-up could be some outside statement, by the President, or Fed Chairman or, by way of a more specific example, the CEO of Bear Sterns, Alan Schwartz, who two days before it went bankrupt made a public statement saying that Bear Sterns was in solid financial condition; he may have been correct, but his audience started demanding their cash, which then set off the crash in Bear Sterns' liquidity, stock, and its demise (Blodget, 2008). This "attractor" was a self-fulfilling prophecy in the opposite direction. Usually, any even a slightly negative statement by a person thought to be knowledgeable, like the Fed Chairman, will set off a volatility incident.

Our perspective is that the financial phenomena we describe in Section III clearly fall into category 3. This means that resilience engineering can't happen successfully unless we develop tools for early diagnosing of the TIEs that set off "circular causal dynamics," and additional tools for stopping the build-up from Triple Point to Critical Point and significant market crashes, as we describe next.

While we accept Pariès' typology, we don't believe resilience in financial systems goes from "nominally" to "weakly" to "strongly emergent resilience." We do agree that intra-system, selforganized emergent resilience is predictive in category 1 phenomena and has some probability of occurring via simple-rules in category 2 . For category 3 financial market phenomena, however, we have to presume resilience may build recursively, but only if instigated by outside influences - usually government interventions (Minsky, 1982, 1986). For category 3 financial systems, then, resilience calls for outside interventions; the resilience development "tools" have to come from outside existing financial-market systems.

\section{WE TAKE AN ECONOPHYSICS APPROACH}

\section{A. BACKGROUND}

Mirowski (1989) achieved notoriety in economics for his book, More Heat than Light, in which he describes economics as thermodynamic-equilibrium-based "social physics"connected to Newtonian physics as it has been since Adam Smith's Wealth of Nations (1776). Then we see Lord Kelvin's formation of the $1^{\text {st }}$ and $2^{\text {nd }}$ Laws of Thermodynamics in 1849 , Boltzmann's creation of statistical mechanics in 1877, Bachelier's discovery of the random walk in 1900, and Einstein's application of it to Brownian motion in 1905. After Boltzmann, we see the application of statistical mechanics to late $19^{\text {th }}$ century marginalism and Marshalian neoclassical economics on thermodynamic equilibrium. Bachelier's invention of the random 
walk gave rise to faith in the "average" stock price and Gaussian statistics (Fox, 2009). No one is more central to making economics a physics-like science than Samuelson. His goal was to reduce the logic of neoclassical economics to mathematical equations. This culminated in his book of 1947, Foundations of Economic Analysis, which built from the physics equations of thermodynamics and random walks.

One key difference between economics and physics is that theories in physics are always held accountable to empirical reality (though some times it takes a long time for truth to emerge). In economics, however, there is much less evidence that economists' faith-based micro- and macroeconomics math is connected to empirical reality. Consider:

- "No economic theory was ever abandoned because it was rejected by some empirical econometric test...." (Aris Spanos, 1986, p. 660);

- "It seems to me that as a profession we don't value empirical work very highly." (p. 180). "I believe there are very few empirical enterprises in economics that have any significant possibility of affecting how economists think about how economies operate." (p. 193) (Edward Leamer, 1990).

- "We don't genuinely take empirical work seriously in economics. It's not the source by which economists accumulate their opinions, by and large" (p. 7) (Leamer, quoted in Kennedy, 2003)

- "I invite the reader to try and identify... a meaningful hypothesis about economic behavior that has fallen into disrepute because of a formal statistical test" (Larry Summers, 1991, p. 139).

Rosser (2008) makes a demonstrable point of the long historical rooting of economics in physics. What makes econophysics different, however, are two key elements: (1) its strict focus on empirical findings based on large data bases; and (2) its emphasis Lévy and Pareto distributions and scalability instead of marginalism and Gaussian statistics. Though early discoveries date back to Pareto (1987), Auerbach (1913), and Zipf (1935, 1941, 1949), the term, econophysics, was neologized by E. H. Stanley in 1995 at a conference on statistical physics in Kolkata, India. Under the econophysics label, then, and often publishing in the econophysics section of the journal, Physica A, econophysicists have discovered a seemingly endless list of findings about long-tailed Pareto-distributed economic phenomena. Instead of universally assuming that economic phenomena invariably trend toward equilibrium, means, and finite variance, we see all kinds of findings to the contrary, some of which are: ${ }^{4}$

- Returns in financial markets (Mantegna, 1991; Levy and Solomon, 1997; Gopakrishnan et al., 1999; Sornette \& Johansen, 2001; Farmer \& Joshi, 2002; Stanley, Plerou, \& Gabaix, 2008; Wong, Lian, Cheong, 2009);

- Economic shocks and growth rates (Canning et al., 1998; Lee et al., 1998; Stanley et al., 2000; Ormerod \& Mounfield, 2001; Podobnik et al., 2006; Redelico et al., 2008);

- Firm size and growth rates (Stanley et al., 1996; Takayasu \& Okuyama, 1998; Chou \& Keane, 2009; Cirillo \& Husler, 2009; Glaser, 2009; Zhang, Chen \& Wang, 2009);

- Income and wealth (Levy \& Solomon, 1997; Drăgulescu \& Yakovenko, 2001; Di Guilmi, Gaffeo \& Gallegati, 2003; Chatterjee, Yarlagadda \& Charkrabarti, 2005; Clementi \& Gallegati, 2005; Patriarca, Chakraborti \& Germano, 2006; Sinha, 2006; Jayadev, 2008; Yakovenko \& Rosser, 2009);

- City sizes (Rosser, 1994; Gabaix, 1999; Batty et al., 2008; Bettencourt, Lovo \& West, 2008; Garmestani, Allen \& Gallagher, 2008; McKelvey, 2010);

- Scientific discoveries (Plerou et al., 1999; Sornette \& Zajdenweber, 1999);

\footnotetext{
${ }^{4}$ Our list takes off from, alters, and extends a list begun by Rosser (2008).
} 
- Networks (Barabási, 2002; Battiston \& Catanzaro, 2003; Barabási \& Bonabeau, 2003; Ravasz \& Barabási, 2003; Sornette et al., 2004; Gay \& Dousset, 2005; Souma et al., 2006; Chmiel et al., 2007; Santiago \& Benito, 2008; Song, Jiang \& Zhou, 2009).

- Stock market volatility dynamics (Ghashghaie et al. 1996; Arneodo et al. 1998; Muzy et al. 2001, Gençay et al. 2004, Ellis \& Hudson, 2007; Kang \& Yoon, 2007; Mu \& Zhou, 2008; Wei \& Wang, 2008; Jiang et al., in press);

- Detecting stock market bubbles; predicting crashes (Struzik, 2001; Zhou \& Sornette, 2002, 2003; Grech \& Mazur, 2004; Cajueiro \& Tabak, 2004; Sornette \& Zhou 2006; Masakawa, 2007; AlvarezRamirez et al., 2008; Du \& Ning, 2008; Eom et al., 2008; Sanchez Gránero et al., 2008; Kumar \& Deo, 2009; Yan, Woodard \& Sornette, 2010; Yalamova, 2003, 2010).

We end this background section about econophysics by quoting two paragraphs from a recent article by Didier Sornette and colleagues:

The research presented here is highly unconventional in financial economics and will swim against the convention that bubbles cannot be diagnosed in advance and crashes are somehow inherently impossible. But as Einstein once said: "Problems cannot be solved at the same level of awareness that created them." We thus propose a kind of Pascal's wager: Is it really a big risk for the community to explore the possibility of changing the conventional wisdom and open new directions for the diagnostic of bubbles, ones that may eventually lead to important policy and regulatory implications? (our italics)

This research may have indeed global impacts. We confront directly the wide-spread belief that crises are inherently unpredictable. If one can convince that some crises can be diagnosed in advance and, what is even more important, if one can quantify the associated uncertainties, this may help economists and policy makers develop new approaches to deal with financial and economic crises. (our italics) (Yan, Woodard \& Sornette, 2010)

We develop resilience engineering applied against financial engineering by using the formation of a power-law (PL) distribution of stock market volatility dynamics as a tipping point. At this tipping point, we suggest that a set of stronger-to-weaker resilience devices may be applied. We build directly from the existing econophysics articles focusing on volatility dynamics, multifractality, and the Hurst exponent.

\section{B. KEY ECONOPHYSICS ELEMENTS FOR RESILIENCE ENGINEERING}

Econophysics is the most recent phase of complexity science, since it studies the scalable outcomes of emergent phenomena (Brock, 2000; Gell-Mann, 2002). While the econophysics findings in Physica A, are mostly empirical, the theoretical basis for explaining why PL distributions dates back to Mandelbrot's works of 1963a,b and 1982, among many others, and more recently works of Schroeder (1991), West and Deering (1995), Mantegna \& Stanley (2000), Vasconcelos (2004), and Newman (2005). Its focus is on how order creation actually unfolds once the forces of emergent order creation by self-organizing agents - such as biomolecules, organisms, people, or social systems - are set in motion. Key parts of this phase are fractal structures, PLs, and scale-free theory (SFT). In his opening remarks at the founding of the Santa Fe Institute, Gell-Mann (1988) emphasized the search for SFTs - simple ideas that explain complex, multi-level phenomena. Brock (2000) goes so far as to say that "scalability" is the core of the Santa Fe vision - no matter what the scale of measurement, the phenomena appear the same and result from the same causal dynamics. Gell-Mann (2002) concludes his chapter, "What is Complexity?" with a focus on scalability. 
More narrowly defined, econophysicists apply concepts of statistical physics to financial systems. In situations where one can't write an equation to explain the dynamics of all the relatively "microscopic" entities comprising a financial system, econophysicists apply scaling concepts to explain macro-level dynamics without having to first create the equation of "microscopic" interacting entities. Econophysics especially applies to explaining how stocktrading dynamics shift from trading according to EMH to trading that becomes embedded in the development of a bubble-build-up to the crash point (Jiang et al., in press; Zhou \& Sornette, 2003; Yan, Woodard \& Sornette, 2010), as follows:

a) Fractals. Consider the cauliflower. Cut off a "floret;" cut a smaller floret from the first floret; then an even smaller one; and then even another, and so on. Despite increasingly small size, each lower-level component performs the same function and has roughly the same design as the floret above and below it in size. This feature defines it as fractal. Fractals can result from mathematical formulas - as shown in Mandelbrot's "Fractal Geometry" (1982). We are more interested in fractal structures that stem from adaptive processes-like the cauliflower-in biological, social, and for this book financial, contexts. In fractal structures the same adaptation dynamics appear at multiple levels. McKelvey et al., (2010) cite 19 studies showing adaptationbased predator/prey fractal dynamics. Zanini (2008) argues that the same effects hold for merger and acquisition activities in business niches.

Fractal structures are often indicated by PLs. The econophysicist Barabási (2002) connects scalability, fractal structure, and PL findings to social networks. He shows how networks in the physical, biological and social worlds, are fractally structured such that there is a "rank/frequency" effect - an underlying well-formed Pareto distribution showing many sparsely connected nodes at one end and one very well connected node at the other plotted using log scales. For example, if plotted as a double-log graph, the Pareto-distributed progression of increasing numbers of connections from, say, small airports to giant ones like Heathrow and Atlanta, appears as a negatively-sloping straight line.

b) PLs. A well-formed Pareto rank/frequency distribution plotted in terms of double-log scales appears as a PL distribution — an inverse sloping straight line; often called Zipf's Law. PLs often take the form of rank/size expressions such as $F \sim N^{-\beta}$, where $F$ is frequency, $N$ is rank (the variable) and $\beta$, the exponent, is constant. In a typical "exponential" function, e.g., $\mathrm{p}(y) \sim$ $\mathrm{e}^{(a x)}$, the exponent is the variable and $e$ is constant. The now famous PL "signature" dates back to Auerbach (1913) and Zipf (1935, 1949). Andriani and McKelvey (2007, 2009) list 140 kinds of PLs in physical, biological, social, and organizational phenomena. Stanley et al. (1996) find that manufacturing firms in the U.S. show a fractal structure, as does Axtell (2001). See also Newman (2005), Newman et al. (2006), Clauset et al. (2007), Glaser (2009), and Chou and Keane (2009).

Since PLs mostly appear to be the result of self-organization, they often if not always, signify active self-organization processes at work maintaining some kind of self-organized criticality. Thus, Ishikawa (2006) shows PLs in adaptive and changing industries (as opposed to static ones). Podobnik et al. (2006) show PLs in the stock markets of transition economies. The Dow Jones market capitalizations of the 30 largest U.S. publicly traded firms show a PL-again, evidence of fractals when traders are free to buy and sell as they wish (Glaser, 2009). ${ }^{5}$ Iansiti and

\footnotetext{
${ }^{5}$ Correlation between power law and straight line is 0.992. Data are Dow Jones stock market prices in 1960. Firms include AT\&T, GM, IBM, Standard Oil, Du Pont, and GE.
} 
Levien (2004) show that the software industry is the most resilient across the 2002 dot.com bust. As compared to the machinery and chemical industries, Zanini (2008) shows the software industry to be much more Pareto distributed. Glaser (2009) shows that the software PL correlates with a straight line at 0.998 .

c) SFTs explain why fractals appear and behave as they do. Though scalability may have been at the core of the Santa Fe vision, scale-free theories have only recently begun to be consolidated and featured collectively by the econophysicists (West \& Deering, 1995; Mantegna \& Stanley, 2000; Vasconcelos, 2004; Newman, 2005). The key feature that sets scale-free theories apart from most social science theories is that they use a single cause to explain fractal dynamics at multiple levels. The earliest dates back to 1638 - Galileo's Square-Cube Law; the cauliflower keeps subdividing to keep its surface area at a constant ratio to its growing volume. Explanations for why some structures have adaptive success while others do not, range from biology to social science. If the same theory or principle applies to microbes and to organizations, it is assuredly scale-free. Andriani and McKelvey (2009) describe 15 scale-free theories applying to firms.

\section{THE 2007 LIQUIDITY-CRISIS PRECURSORS AS AN EXAMPLE}

It is rather strange that even though Mandelbrot's attention to scaling and fractals in financial markets dates back to his $1963 \mathrm{~b}$ article, none of the scale-free theories we believe apply to financial meltdowns appear in his works. In the following sequence of developments leading up to the August 2007 liquidity crisis and its Great Recession consequence, we try to identify relevant TIEs, follow-on growth spirals leading up to what are called the Minsky Moments, and then the scale-free theories (SFTs) that appear to apply at that time, given the financial elements present. ${ }^{6}$ We follow TIEs with a mention of how various events spiraled out of control and then which SFTs best explain the various ways traders' tensions and connectivities caused the eventual market crash. Minsky Moments and SFTs are discussed in later sections.

1973: Derivatives invented as safe investment formulas applied to foreign currencies; allowed high leverages; currencies begin to be traded in financial markets; Black \& Scholes publish their option-pricing formula based on derivatives, ${ }^{7}$

- TIEs: Investment houses start using derivatives as safe investments;

- Spirals: Money involved and leverage used grows $\rightarrow$ spreads around the globe. The crash induced by the failure of Long Term Capital Management in 1998 shows that fail-safe beliefs, approaches, \& formulas eventually aren't;

- SFTs: Contagion bursts: banks substitute for crowded rooms, buses, and planes, thereby spreading contagion more quickly. Phase transition $1^{\text {st }}$ critical value threshold lowered; use of derivatives lowers the $1^{\text {st }}$ critical value threshold such that high-risk \& high-leverage investment practices emerge with less initial risk.

1979: The IBM PC begins the development of computational finance and complex financialengineering arbitrage instruments;

\footnotetext{
${ }^{6}$ Sources: Cooper (2008), Morris (2008), Phillips (2008), Soros (2008), Wolf (2008), Baker (2009), Cohan (2009), Foster \& Magdoff (2009), Krugman (2009), Rogoff \& Rogoff (2009), Sorkin (2009), Gilbert (2010).

${ }^{7}$ Justin Fox (2009) observes that while Bachelier (1914) deserves credit for the initial "true breakthrough on options pricing" (p. 147), Black and Scholes produced the first acceptable formula in 1973, which builds from derivative pricing.
} 
- TIEs: Computers and programming foster the invention of all sorts of investment formulas; the complexity of formulas and interacting formulas buried in code grows; makes risk-implications more obscure; makes detection more difficult;

- Spirals: Computer memory and speed increases $\rightarrow$ programs and investment methods become even more complex $\rightarrow$ supply increases demand $\rightarrow$ demand increases supply $\rightarrow$ their use grows worldwide;

- SFTs: Irregularity generated gradients: individually insignificant innovations plus positive feedback fuel rapid, unwatched, and unchecked growth. Phase transition: $1^{\text {st }}$ critical value threshold lowered (computers become cheaper; "quants" move into Finance); emergent degrees of freedom in re-combinations of high-risk tranches are obscured by the complexity of the securitization packages.

1985: Mortgage-backed securities (hereinafter "mortgage-backs") are invented; ${ }^{8}$ tranches are created to mix strong and weak mortgages into loan securitization packages so as to reduce risk; unfathomably complex computer-based loan securitization instruments materialize;

- TIEs: Value of houses treated like value of cash in a checking account; investment banks begin to base investment strategies on mortgage-backed assets;

- Spirals: Tranch-based, financial-engineering designed securitization packages take many forms and grow into \$trillions in value $\rightarrow$ leverage increases to $50 / 1 \rightarrow$ goes worldwide $\rightarrow$ leverage reaches as high as 100/1;

- SFTs: Combination theory: increased complexity of securitization packaging results in interactive combinations of high-default-risk tranches that multiply into securitization packages more likely to show skew distributions; \& Pareto extremes. Phase transition: securitization packages lowered the risk threshold for taking advantage of mortgage-backs; what emerged was a complex obscuritization of mortgage-backed risk vulnerabilities.

1999: Glass-Steagall Act is repealed in 1999;

- TIEs: "Deposit-style" banks begin taking investment-bank kinds of risks; Citigroup buys Smith Barney; this begins the de-separation of depositor banks from investment banks; all banks could take highly leveraged high-risk investment actions;

- Spirals: Spreads to many, many banks $\rightarrow$ spreads to government-based banks (Freddie Mac, Fanny Mae) and insurance companies such as AIG (others buy small banks so they can then begin to pursue risky investments like bigger banks \& investment banks) $\rightarrow$ spreads worldwide;

- SFTs: Irregularity generated gradients: contagion is bank by bank as opposed to random individuals; speeds up gross risk-taking by banks. Spontaneous order creation: banks, as agents, communicate, learn, influence each other with positive feedback effects.

2000: $\$ 609$ billion of foreign reserves in U.S. Treasury securities. By the end of 2004, amount grows to $\$ 1.2$ trillion; $^{9}$ amounts to $\$ 3$ trillion by $\mathbf{2 0 0 8} ;^{10}$

- TIEs: Bond interest rates sink; cheap borrowing; imports cost less than U.S.-produced products;

- Spirals: Fed. discount rate sinks to 0.75 in November $2002 \rightarrow$ real estate speculation grows $\rightarrow$ risk of mortgage-backs grows $\rightarrow$ debt skyrockets to eventually amount to $\sim 335 \%$ of U.S. GDP;

- SF Theory: Spontaneous order creation: people learn to use cheap money to refinance their houses; often several times; mortgages increase in value; debt-based spending increases; fragility of the economy increases;

2000: Housing bubble starts in U.S., UK, Spain, and Australia; Bush Admin. Policy to foster more home ownership, especially among minorities;

\footnotetext{
${ }^{8}$ The mortgage-backed security was invented by UCLA's Professor Richard Roll while he was visiting at Goldman Sachs; he was their Director of Mortgage Securities Research from 1985-1987.

${ }^{9}$ Fed Reserve Bank of San Francisco (2005), "Economic Letter." http://www.frbsf.org/publications/economics/letter/2005/el2005-17.html.

${ }^{10}$ Total foreign holdings of U.S. Treasury securities are over $\$ 3$ trillion by Dec. 2008 http://www.treas.gov/tic/mfh.txt. China's holdings amount to \$744billion.
} 
- TIEs: Prices rise instantly when house first goes on market; bidding takes place; house sold within an hour (typical of LA); millions of people try to buy their first house;

- Spirals: Bush policy: “Get Americans (especially minorities) into their own homes;" mortgages given without credit or income checks; more people buy houses; demand pushes up prices; high prices mean fewer defaults on loans since house can be unloaded at higher price; less risk $\rightarrow$ more home buying $\rightarrow$ higher prices $\rightarrow$ less risk of default $\rightarrow$ more speculation by real estate brokers $\rightarrow$ more buying $\rightarrow$ etc.;

- SFTs: Phase transition: $1^{\text {st }}$ critical value threshold lowered; fosters emergent low-interested based mortgage policies. Contagion bursts: banks stop asking for credit \& income statements; borrowers learn about cheap mortgages; towns and builders learn to build housing developments to take advantage; real estate agents start speculative buying, reselling.

2002: 5- \& 2-year sub-prime "teaser" loans used to buy houses at low interest emerge; $1 \%$ "interest-only mortgages appear;

- TIEs: Fed discount rate was 1.25 in December of 2001 and reached its low of 0.75 in November of 2002; sub-prime mortgages increase; real estate speculation increases;

- Spirals: Teaser fixed-rate mortgages increase $\rightarrow$ Fed discount rate increases to $6.25 \%$ by July 2006 , i.e. $6 \%$ higher 5 years later when the teaser loans turn to variables $\rightarrow$ property taxes increase with value of home $\rightarrow$ vast increase of mortgage-backed investment funds available but risk increases greatly as well;

- SFTs: Contagion bursts: agents connected to banks speeds up the spread of the teaser-loan idea. Preferential attachment: Some banks (e.g., Countrywide, IndyMac, WaMu, Freddy Mac, Fanny Mae, etc.), became especially well known for offering teaser loans with few questions asked; they then had links to other banks (which were often later acquired).

2003: Annual volume of annual securitization issuance reaches $\$ 4$ trillion as banks leverage deposits up to a 30/1 to 50/1 and even 100/1 (no limits to leverage in Europe) margins on mortgage-backs; goes worldwide by 2005 ;

- TIEs: Each new subprime mortgage is a TIE

- Spirals: mortgage-backs $\rightarrow$ new kind of securitization package as a TIE $\rightarrow$ securitized packages increase and leverage increases $\rightarrow$ downside risk is increasingly likely $\rightarrow$ economic fragility increases;

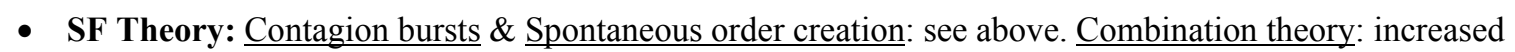
complexity of securitization packaging with increasing leverage results in combinations of skew distributions that compound into Pareto extremes and the ultimate panic and collapse of bank liquidity.

2005: 5-year teaser loans begin to expire; mortgage defaults increase; housing bubble expires toward end of year; the Minsky Moment appears;

- TIEs: This is the beginning of post-teaser defaults; more teasers expire in next 2 years; outcome is the 2007 liquidity crisis;

- Spirals: Minsky's phrase "stability causes instability" begins to apply: Housing price bubble $\rightarrow$ inflation; inflation worries increase $\rightarrow$ Fed. increases the discount rate $\rightarrow$ mortgages interest rates increase $\rightarrow$ spread between teaser rate and post-teaser variable interest rate increases; the foregoing + increasing property taxes $\rightarrow$ increasing mortgage default rate $\rightarrow$ undermining the value of mortgage-backs $\rightarrow$ economic fragility;

- SFTs: Same as for 02-03 above, except in reverse, i.e., after the Minsky Moment(s).

2006: Bubble in housing prices ends; house prices begin their decline in the U.S. in January; mortgage defaults skyrocket; the Minsky Moment has passed;

- TIEs: Increasing defaults; more banks at risk; incredibly complicated packages; very high leverage; worldwide;

- Spirals: Subprime teaser loans begin to expire $\rightarrow$ defaults and foreclosures begin to rise $\rightarrow$ housing market and construction collapse $\rightarrow$ mortgage-backed securities become toxic $\rightarrow$ liquidity begins to collapse;

- SF Theory: Contagion bursts: but now fuelling rapid decline rather than rapid growth. Preferential attachment: in reverse; i.e., the networks and attachments created up to 02-03 now spread panic and decline. 
2007, Summer: Subprime crisis hits; home-mortgage defaults and foreclosures skyrocket in the U.S.; Bear Stearns' collapse begins in July; broader bank failure in U.S. in August; UK's Northern Rock fails in September.

2007, December 1st: Recession begins in December (stipulated after-the-fact by the NBER).

2008, September: Crisis-panic hits; Paulson asks for \$700B bailout; U.S. liquidity crisis spreads worldwide; The Great Recession begins.

As one may see, there are many instances over the past four decades where Holland's (2002) TIEs spiraled up and add momentum to the bubble build-up; phenomena explained by six different SFTs from complexity science. Especially relevant is "combination theory."

\section{EXPLAINING HERDING BEHAVIOR \& THE BUBBLE BUILD-UP}

The Economist finally admits that bank trading doesn't follow Bachelier's random walk and Fama's (1970) efficient market hypothesis (EMH):

BANKS mimic other banks. They expose themselves to similar risks by making the same sorts of loans. Each bank's appetite for lending rises and falls in sync. What is safe for one institution becomes dangerous if they all do the same, which is often how financial trouble starts. The scope for nasty spillovers is increased by direct linkages. Banks lend to each other as well as to customers, so one firm's failure can quickly cause others to fall over, too. ${ }^{11}$

While we paid tribute to Mandelbrot's initiating insights into the fractal structure of various kinds of markets in Section II, including stock markets, at this point we pay special tribute to Minsky's early positive-feedback explanations of stock-market volatility dynamics and Minsky Moments. We start with a short review of Minsky's perspective and then introduce scalability theory and give background definitions of the relevant SFTs. We end this section by focusing on the two key elements that usually have to be present for scalability to develop: tension and connectivity.

\section{A. Positive Feedback AND Minsky Moments}

Cooper notes that Mandelbrot's thinking about financial crashes can easily be translated into Minsky's 'self-reinforcing positive feedback processes..." (2008: 150). Many commentators now point to Minsky's famous phrase: "stability creates instability." Moments" ${ }^{\prime 13}$ are the inflection points where positive-feedback forcing stock markets up in value reverses to force them down. Wolfson (2002) boils Minsky's perspective down to four key positive-feedback cycles (positive feedback $=\mathrm{PF}$ ):

- Financial Fragility. PF spiral up: Optimism increases; attitudes toward debt and risk change; liability structures change; the financial system becomes increasingly fragile; as debt increases, fragility increases. Minsky Moment.

\footnotetext{
${ }^{11}$ Finally, even The Economist (2009c, 2010) — the den of free markets and EMH—admits to the connectivity effect as a basis of crashes in the financial system.

${ }^{12}$ The most relevant works by Minsky are: Can "It" Happen Again? (1982), and Stabilizing an Unstable Economy (1986).

${ }^{13}$ The term, "Minsky Moment" was coined by Paul McCulley in 1998 during the LTCM-induced crash (Lahart, 2007). It is best defined by Lahart as "the time when over-indebted investors are forced to sell even their solid investments to make good on their loans, sparking sharp declines in financial markets and demand for cash that can force central bankers to lend a hand." In short, it is the point when speculation based on over-borrowing tips over into a market crash.
} 
PF down: As short term debt increases liquidity declines; speculative and Ponzi firms increase; firms have to increase their short-term debt as liquidity decreases and interest rates rise so as to pay off long-term debt.

- Movement to the Brink. PF spiral up: As the speculative bubble increases, the Fed increases interest rates to slow it down. Speculative hedge funds, banks and Ponzi firms have to keep increasing debt as interest rates increase. Minsky Moment. PF down: The Fed, in raising its discount rate from a low of $0.75 \%$ in November 2002 to $6.25 \%$ in June of 2006 , sets off the financial crisis by overly increasing the debt load of all those speculating — higher interest $\rightarrow$ more debt expense $\rightarrow$ means more borrowing $\rightarrow$ means higher interest-etc.

- Surprise event. PF spiral up: As a financial system becomes more speculative it become more vulnerable to "not unusual" (surprise) events, like the failure of a large bank, or bond default by a foreign country. The more financial fragility the more likely surprise failures. Minsky Moment. PF down: The more failures the more financial fragility $\rightarrow$ the more fragility the more failures $\rightarrow$ etc.

- Debt-deflation. PF spiral up: Financial fragility increases unwillingness to finance investment; less investment reduces profits; reduced profits reduces willingness to invest. Decline in profits leads to debt-deflation which reduces prices, which in turn increases the real value of outstanding debt commitments. Minsky Moment. PF down: The Fed steps in (as has the Obama government) to stimulate the economy. This in turn risks setting of an inflationary spiral which, then, re-sets the stage for another round of inflationary expansion: i.e., the Fed reduces discount rates (down to $0.50 \%$ in December 2008) $\rightarrow$ borrowing increases $\rightarrow$ house prices increase $\rightarrow$ mortgages go down toward subprime levels $\rightarrow$ housing speculation starts $\rightarrow$ house-based bubble starts $\rightarrow$ etc; news reports by 2010 indicate all the requirements are in place for another housing bubble to start.

As Minsky's view shows, there are a variety of self-reinforcing positive feedback processes causing bubble-build-ups in stock markets that sometimes result in dramatic crashes. They begin with low interest rates, initiating events such as new trading rules, hedging techniques, or the development of new derivatives-based products. Individual traders and institutions engage in these initiating events and in the process of learning and adaptation, a bubble develops.

\section{B. TENSION AND CONNECTIVITY}

In his now classic book, How Nature Works (1996), Per Bak starts from his 1987 study of change dynamics in sandpiles (Bak et al. 1987). Falling sand grains are allowed to slowly pile up. Eventually the sandpile becomes high enough and the sides of the sandpile steep enough that sand grains start sliding down its sides to keep re-adjusting its height and the steepness of its sloping sides to maintain stability. Bak called this "self-organized criticality"- the sliding sand grains keep the slope at the same "critical" angle. The degree of steepness of the slope depends on two elements: (1) gravity and (2) the sharp irregularity of the grains. Take away gravity and there is no force causing the grains to slide down the side of the sandpile. Take away irregularity - e.g., shift from falling irregular grains of sand to, say, M\&M Peanuts - and the M\&Ms will not pile up (go try it and see what happens!). Bak also discovered that the size of sand-grain movements ranged from many frequent instances of one or a few grains moving to small avalanches to a rare rather large avalanche - the size and frequency of falling-sand-grain avalanches is PL distributed!

Now, for the financial Crash build-up phenomena we outline above:

1. Instead of gravity, substitute greed, liquidity (i.e., lots of money available needing investment), risk taking, and arrogance and we have lots of tension toward investing to make profits; and

2. Instead of sharp irregularity, substitute human connectivity via phones, email, financial engineers gathered in one office area in a firm, quant types transferring from one firm to another, advertising and advice giving by firms, and especially human copying, herding, and learning abilities, and general interest in learning better approaches for making money and we have high levels of connectivity. 
With this analogy we see that the two critical elements necessary for PL distributions - both tension and connectivity - are obvious in financial market trader behaviors. The many bases of tension coupled with the many bases of connectivity leave little doubt that Minsky's positive feedback, and our several additional SFTs as well, readily characterize financial-market trading phenomena.

\section{FROM MINSKY TO A BROADER SET OF SCALE-FREE DYNAMICS}

As noted in Section III, the key feature that sets SFTs apart from most social-science theories is that they use a single cause to explain fractal dynamics at multiple levels. More specifically, when tension and connectivity are present among a set of agents (stock traders in the foregoing example), there is some likelihood that one or more TIEs will spiral up into an extreme outcome such as a market crash-i.e., a bubble-build-up occurs. We point to many "spiral" examples dating back to 1973 .

While tension resulting from needing to make money or fear of losing money exists all the time, the connectivities giving rise to herd behaviors come and go, or change their nature. Explanations for why some structures have adaptive success via self-organized criticality, while others do not, range from physics to biology to social science. Andriani and McKelvey (2009) describe 15 SFTs applying to organizations and business activities. We have mentioned six of them in the foregoing 2007 liquidity-crisis example:

- Phase transition

- Contagion bursts

- Irregularity generated gradients
- Spontaneous order creation

- Combination theory

- Preferential attachment

In Table 1 we give brief definitions of each SFT and line them up with the various SFTs mentioned above in our history of the build-up the 2007 crisis. The key element here is that there is much growing evidence about all of the TIEs, coupled with growing trader tensions and connectivities, that led up to the 2007 liquidity crisis and market crash. There is not just one SFT; there is not just one point in time that set off the crisis. Instead, we see an accumulation over time of many spirals and at least six SFTs that contributed to the scalability build-up; many scalability spirals have been set in motion since the invention of derivatives in 1973.

\section{>> Insert Table 1 about here $<<<$}

\section{FINANCIAL MARKET PHENOMENA-TOWARD A SCALE-FREE PERSPECTIVE}

We begin with short definitions of market dynamics as defined by the Efficient Market Hypothesis (EMH) (Fama et al., 1965, 1970, 1998), which we label as the Triple Point. Then we define the Critical Point, where market crashes occur, and how markets build-up from Triple to Critical Point.

\section{A. Triple Point}

\section{Defining Market Dynamics}

The Y-axis in Figure 1 measures the risk of a security with respect to the one incorporated in the fundamental valuation. Closer to the Origin, the risk measure in the fundamentals is larger, 
leading to under pricing of stocks. In equilibrium at TPy1, risk is properly incorporated in the fundamental analysis and the price is "fair," while going upward increasing risk-taking behavior underestimates volatility of the firm's underlying fundamentals, which leads to overpricing.

\section{>> Insert Figure 1 about here $<<<$}

Returning to our two types of investors (rational and noise), rational investors evaluate all available information and make their trading decisions based on the ratio of Risk and Return, defining underpriced (buy) and overpriced (sell) stocks. The Y-axis of our financial markets phase diagram measures these decisions by a Risk/Fundamentals ratio. In the base condition (where system complexity is minimal and rational traders hold uniform assumptions), the opposite side of a trade is attributed to liquidity traders in the efficient market paradigm. Sell pressure on the price increases with increase of Risk (on the Y-axis) as investors are predominantly risk averse. We also allow for noise traders either with "incorrect" valuation, or invalid information to come to a decision to sell underpriced and buy overpriced securities. Increasing numbers of such noise traders will lead to a bubble-build-up as we will explain later.

On the X-axis, we focus on the Noise-to-Information trading ratio. We believe that disorder in the market can be measured by the ratio of Noise-to-Information trading. Information trading implies investors can properly process information and act rationally. Close to the origin Information based trading and rationality prevails. If all investors are rational and all trading decisions are information based, we will have homogeneous agents, one-sided trade orders and a "halt" in the market. At TPx1 a balance between information and noise traders sets the market at fair valuation. Conversely, as noise trading becomes increasingly evident in the market, rationality recedes and disorder increases. In normal markets with heterogeneous independent traders and random noise, prices adjust to fundamental (certain) value and anomalies are short lived. Under some conditions (e.g., new technology, trading rules, or formulas such as derivatives, etc.) noise in the market increases and creates information ambiguity. Therefore uncertainty-averse traders switch to non-probabilistic approaches to decision-making.

Moving horizontally from the area of "certainty" to the right, we enter a region of higher information complexity and uncertainty "distinct from the familiar notion of risk," as defined by F. Knight (1921). In uncertain situations many decision-makers prefer to bet on unambiguous events rather than on ambiguous ones (Basili \& Zappia, 2003). This contradicts the appropriateness of probabilistic decision-making. Shackle (1949), developed a theory opposing the subjective probability approach. It is a non-probabilistic decision theory seeking to optimize robustness to failure, or opportunities for windfall profits. Zhang (2006) investigates the role of information uncertainty in price continuation anomalies and cross-sectional variations in stock returns; he shows that short-term price continuation is due to investor behavioral biases, which result in greater price drift when there is greater information uncertainty. We argue that given the random nature of good/bad news, information uncertainty alone can not produce a bubble-build-

up as greater information uncertainty should produce relatively higher expected returns following good news and relatively lower expected returns following bad news.

\section{Triple-Point Dynamics}

We view the lower-left corner as highly unstable, since rational investors are willing to buy the underpriced securities, but there are very few noise traders, who will sell at this price. As a result, the market moves from left to right, thereby crossing the phase boundary; this results in 
falling liquidity as buy orders prevail and price goes up. The basin of attraction is the Triple Point. Note that in the "certainty" area information traders prevail.

The upper left corner is an area of overpricing, news about fundamentals may suggest higher volatility than the risk incorporated in the price. Rational investors with adequate valuation will detect overpricing and place sell orders, the market moves to the right, crosses the phase boundary into the "sell" phase, liquidity falls, and prices adjust to the equilibrium market risk level TPy1. The market moves to the Triple Point.

Over- or under-pricing are a very short-lived phenomena after news (new relevant information) is released. In both cases moving from the "wait" phase either through sell or buy to reach the attractor point (Triple Point $=$ dynamic equilibrium) sees the market cross the phase boundaries. If there is nonlinearity present, there should be a function that experiences abrupt change with a small change in the X-axis (noise/info trading). This also should be related to a jump in the price, as the market quickly adjusts to new information and incorporates the news in the price.

As we move horizontally in Figure 1, from "wait" to "buy" in the area of under -pricing, the liquidity increases, as more noise traders are present. When we cross into the "buy" state characterized by positive demand, the liquidity function changes Similarly, in the overpriced area, when a rational investor wants to sell at $x$ price, the market should move horizontally to find a "noise" buyer. To the right the ratio of noise traders' increases, increasing the ease of trade (liquidity), but after the phase boundary, the market is characterized by negative demand and a sell order faces lower liquidity, i.e. fewer buyers.

According to EMH, these are short-lived anomalies that are arbitraged away. The simultaneous execution of a large number of trades produces efficient outcomes and a dynamic equilibrium between the three states is present. Also according to $\mathrm{EMH}$, all investors are rational and base their decisions on fundamental values. Trading only occurs due to liquidity-need investors, who take the opposite side of the trade. As noted earlier, we define those seeking liquidity as "noise" traders since they are not trading based on information.

\section{B. From triple to Critical Point}

Having shown the Triple Point to be an effective attractor basin, we still need to find a mechanism that will explain the empirical record of extreme events evidenced by stock markets; those that far exceed Gaussian-distributed returns (Baum \& McKelvey, 2006). A normal market incorporates new information into the stock prices efficiently; mispricing of securities is temporary. Information does not create ambiguity, noise in the market is offset by rational decision-making; anomalies are short lived. When the level of noise increases, information ambiguity prevails and market moves to the right in the region of uncertainty, efficient information processing and probabilistic decision-making becomes more difficult.

The region of uncertainty, characterized by the complexity and ambiguity of information, begins at $R 1$ (in Figure 1) and extends to the right $-R 1$ marks the transition from efficient market trading to herding behavior. Rational probabilistic decision-making is impeded and the bimodal demand function (Plerou et al., 2003) signals herding behavior. At $R 1$, information complexity impacts risk-taking behavior such that a market moves to a higher risk/fundamentals area. Information cascading, herding, rule-based trading etc. create a complex network (self- 
organization) among traders and leads to a PL distribution of returns. Therefore we define this area as "fractal."

Sornette $(2003 \mathrm{a}, \mathrm{b})$ presents a general theory of financial crashes and stock market instabilities and asserts that markets exhibit complex dynamics. Moreover, he suggests that large scale patterns of a catastrophic nature result from global correlated-trading processes caused by repetitive interactions that eventually spread across the entire system. A PL distribution punctuated with log-periodic oscillations in the index prices seems to be the signature of an impending crash. Among many other examples, Baum \& McKelvey (2006) also show evidence of PL distribution in the daily log returns of DJSI and NASDAQ; they argue that observed PLs stem from interconnected behaviors that are ever present in social contexts (e.g., stock markets).

\section{THE FOUR REGIONS}

Having defined the Triple and Critical Points, we now have four Regions in Figure 1: Certainty, Uncertainty, Risk, and Fractal. We briefly define each of these Regions as follows:

1. Certainty. Most pronounced at the Origin. Note the points on each axis where the Risk/Fundamentals and Noise/Information ratios equal 1, i.e., TPy1 and TPx1. On the X-axis, accurate information dominates noise. On the Y-axis, risk measured by the volatility of a firm's underlying fundamentals is low relative to that used in the valuation process. Rational traders unanimously agree on the under pricing the closer to the origin the market moves.

2. Uncertainty. To the right of the Triple Point location on the $\mathrm{X}$-axis, traders lose contact with any reliable means of attaching true value to information about a particular stock/company. Complexity and ambiguity of information takes over the market. While uncertainty keeps increasing towards $R 2$, market becomes vulnerable to chaos-i.e., bifurcations due mainly to external anomalies hitting a market. Price continuation anomalies are increasing as uncertainty levels increase.

3. Risk. Above the location of the Triple Point on the Y-axis, traders move away from simply trading based on knowledge about the current "fundamental" value of a stock/firm to start betting on future value. A rational bubble emerges when market price depends on its own expected rate of change reminiscent of the models of Blanchard (1979) and Blanchard and Watson (1982). Risk increases up to the location of the Critical Point on the y-axis. Above this point we show "Chaotic Risk;" this is the point where risk-taking becomes vulnerable to chaos-bifurcations that can set off significant crashes.

Note that we show Knight's (1921) risk, uncertainty, and certainty as juxtaposed at the Triple Point. This is the core explanation underlying EMH - traders leaning toward all three situations trade concurrently with quick adjustments of the market shifting toward one or the other of the three conditions.

4. Fractal. The Region between the Triple and Critical Points is notable for increasingly dramatic volatility incidents. Since there is growing evidence that many of these incidents follow fractal patterns, we label the region Fractal. This region corresponds to the bubble regime (Sornette 2003a ) where non-stationary increasing volatility correlations are reported. Moreover, regime switches between "normal" and "bubble" comprise a dynamical model that recovers all the stylized facts of empirical prices. This is what we focus on next.

How much time does the Dow Jones, for example, spend in the fractal region? Note from Figure 1 that, as risk and uncertainty increase, traders end up in the fractal region. "Tradition" and EMH in Finance hold that it spends most of the time at the Critical Point. For empiricists this is represented by GARCH (generalized autoregressive conditional heteroskedasticity) (Bollerslev, 1986). But as one can see in Figure 2, there are many market variances well above the "GARCH line" (which is in black in the Figure).

\section{>> Insert Figure 2 about here $<<<$}


Mandelbrot calculates that

...by the conventional wisdom, August 1998 simply should never have happened.... The standard theories...would estimate the odds of that final, August 31, collapse, at one in 20 million - an event that, if you traded daily for nearly 100,000 years, you would not expect to see even once. The odds of getting three such declines in the same month were even more minute: about one in 500 billion (p. 4).... [An] index swing of more than 7 percent should come once every 300,000 years; in fact, the twentieth century saw forty-eight such days. (Mandelbrot \& Hudson, 2004: 13)

In fact, different market behaviors around the Triple Point and between Triple and Critical Points exist. For sure, on a daily basis EMH behavior is more abundant. But market behavior in the Fractal region is also present and often with greater consequences. It seems obvious that the argument between Fama et al. and Mandelbrot et al. is passé. It is time to pay equal attention to both regions. The number of days the market spends at the Triple Point are considerable. The costs stemming from what happens in the fractal region, however, are less frequent, but not as infrequent as some would want us to believe, and the costs of ignoring this region are often very high indeed. This leads to our interest the $R 1$ tipping point, as opposed to arguments favoring one or the other kind of trading behaviors.

\section{EXPLAINING BUILD-UP TO THE CRITICAL POINT: MEASURING FRACTALITY}

A "fractal dimension" allows us to measure the degree of complexity by evaluating how fast measurements increase or decrease as scale becomes larger or smaller. The methods for measuring fractal dimension rely heavily on the PL, which allows extrapolation and prediction over a wide range of scales. PLs describe empirical scaling relationships that are emergent quantitative patterns of structure (A) or dynamics (B) that are self-similar or fractal-like over many orders of magnitude. The Hurst exponent is related to the fractal dimension, which gives a measure of the roughness of a surface. The relationship between the fractal dimension, $D$, and the Hurst exponent, $H$, is:

$$
\boldsymbol{D}=\mathbf{2}-\boldsymbol{H}
$$

The Hurst exponent provides a measure of whether the data are a pure random walk or have underlying trends. When an autocorrelation has a very long (or mathematically infinite) decay, the series is defined as having long memory.

\section{A. PLS of RETURNS}

When EMH applies, prices follow random walks; prices are unpredictable as their changes efficiently incorporate randomly arriving information to the market. The logarithm of prices measures returns and follows a Gaussian distribution. There is sufficient empirical evidence showing that extreme events lying outside the three standard deviation limit allowed by the normal distribution are observed much too frequently to be deleted as random anomalies (Mandelbrot \& Hudson, 2004). They note that in stock trading, daily returns that are seven standard deviations away from the mean occur 10,000,000 times more frequently than would be the case for random data!

The most popular way of showing PLs in the distribution of returns is to plot the log of the number of observations against the log of the return size and thereby produce in inverse sloping line that is the PL indication. This method has been questioned (Clauset et al., 2007) and has received some critical remarks for being overused, but even so, the finance literature provides 
ample evidence with precise methodology pertaining to the existence of PLs in the distribution of index-price returns. We illustrate this in Figure 3, which shows a PL distribution of the stockprice changes in DJIA, which are pretty close to a perfect PL.

\section{$>>>$ Insert Figure 3 about here $<<<$}

We are not going to discuss this evidence further, as we believe it does not contribute much to the goal of building resilience - we mention it to establish the legitimacy of PL descriptions of market phenomena. Mostly, this statistical method has been used to give information about events that have already happened rather than about the dynamics of stock-price determination and the change in traders' behaviors, which underlie the self-organization of stock trading. Following these dynamics, we believe we are able to detect the threshold level of information complexity that leads to herding, self-organization, and loss of agents' heterogeneity.

\section{B. PLs of The AutoCorrelation Function (ACF)}

In the Efficient Market regime, returns are unpredictable because they do not show discernable correlation. Time series analysis of these prices detects very fast (exponential) decay of the ACF, e.g., one cannot predict tomorrow's price from the observation of today's, yesterday's, or even prices two days earlier, since they are not correlated. Volatility measured by the variance of the stock returns has short memory-i.e., it's essentially random. Time series are modeled as random and independent using the AutoRegressive Moving Average process (ARMA). Moreover, extended time series analysis defines the AutoRegressive Integrated Moving Average (ARIMA) model as a generalization of an ARMA model. When data show evidence of non-stationarity, there is an initial differencing step (i.e., taking the difference between adjacent observations is an example of first-order differencing). After this step, the series are stationary and can be analyzed using tools designed for random processes since the non-stationarity is removed. If the differencing step is an integer, e.g. equals 1 , i.e., $X(t)-X(t-$ $1)=1$, it appears to create no contradiction within the realm of EMH trading; prices follow a $1^{\text {st }}$ order integration process for which econometric tools are widely accepted; $\left(2^{\text {nd }}, 3^{\text {rd }}\right.$, etc., orders are treated similarly).

The standard assumption of an integer-integration order is arbitrary. Allowing for fractionalintegration order leads into the world of fractals, which creates the division between efficient market (and the random - in most cases linear-paradigm) and the "complexity" and of fractal models. In a fractal-market regime, returns are still not predictable but volatility is predictable (Poon \& Granger, 2003). Classic econometrics shows the clustering of volatility but does not capture long-memory in the volatility of returns unless it allows for fractional integration in the models, i.e., the differencing step can be fractional as opposed to only accepted as integer.

If we have a non-stationary process that becomes stationary after differencing but the differencing operator is fractional $0<d<1$, we enter the realm of fractals. This is a sign that some structural changes taking place in a market will show up in the long memory of volatility movements. The hyperbolic (slow) decay of the ACF reveals dependence, correlation, and feedback between traders - which can lead to imitation, herding, and rule-based trading. Our hypothesis is that as information becomes more expensive and/or complex and ambiguous, such that the market cannot find its way back to equilibrium and herding behavior and rule-based trading begin to dominate. The long memory in the volatility of stock returns has already found its way into econometrics models such as ARFIMA and FIGARCH. Given that many time series exhibit very slowly decaying autocorrelations, the advantages of Autoregressive Fractionally 
Integrated Moving Average models with hyperbolic autocorrelation decay seems clear (as opposed to models such as ARMA processes, which have exponential or geometric decay). The stationary stochastic processes frequently referred in financial time series, such as ARCH (Engle, 1982), GARCH (Bollerslev, 1986), IGARCH (Engle \& Bollerslev, 1986), and EGARCH (Nelson, 1991) all have short memory about volatilities. A weakly stationary process can show long memory if its ACF has a hyperbolic decay.

Though it seems quite logical and expedient to embrace the entire spectrum of volatility clustering, one can only wonder why there is so much resistance to accepting fractals as part of financial-asset pricing models. Among the reasons might be the dense covariance matrix they create or that the process does not possess the martingale property. Our view is that these are minor and avoidable technical details. More importantly, there is as yet no unifying theory that allows for both efficient market equilibrium and anomalies that break through the threshold of information complexity, which then create conditions for self-organization, interdependence, and herding behavior among the market participants - i.e., correlated behaviors. Information cascades, herding, and feedback loops are not part of an EMH-style market presumably composed of independent rational investors.

If time series exhibit long memory, they display significant correlations between observations separated in time - i.e., the correlation does not go to zero for a long lag. Therefore we focus our discussion around the evidence of increased price-volatility persistence in periods before crashes. Translated into the language of PLs associated with extreme events, we point to the appearance of PLs in the ACF of volatility, as shown in Figure 4:

\section{$>>>$ Insert Figure 4 about here $<<<$}

The ACF of $\log$ returns is effectively zero for lag $>2$, while the ACF of log-return absolute values (as a straightforward measure of volatility) decreases very slowly and remains positive, even after a lag of 500, before decaying to zero. Such results suggest that the returns of the stock market are uncorrelated while their volatility has long-range dependence. A logarithmic-scale plot of the autocorrelation function gives the same visual illustration of PLs as described in our explanation of PL distributions above. Long-memory is defined mathematically in terms of autocorrelation. The time series of the absolute value of returns exhibits autocorrelation, when return $\left|r_{i}\right|$ is correlated with $\left|r_{i-s}\right|$ and $s$ is a measure of time increment. The autocorrelation function $\rho$ takes a PL form with constant $\mathrm{C}$ and exponent $\alpha$ :

$$
\rho(s)=\mathrm{Cs}{ }^{-\alpha}
$$

The fractional integration parameter $\alpha$ of the ACF is related to the volatility scaling (Hurst) exponent as:

$$
H=1-\alpha / 2
$$

Volatility is random if the Hurst exponent is equal to $1 / 2$, which indicates totally random, socalled "Brownian motion" movements. Volatility persistence as measured by the Hurst exponent increases above $1 / 2$ during periods of increased information complexity. More specifically, if $H>$ $1 / 2$, rule-based trading, herding, imitation, and increased mutual influence among traders leads to log-periodic oscillations of prices appearing as precursory bubble-build-up patterns before crashes-i.e., during the build-up between Triple and Critical Points in Figure 1.

The self-organization process causing the foregoing market dynamics shows up in the form of PL distributions of returns as well as in a PL of the volatility. Yalamova (2003) shows the 
increasing persistence in volatility as measured by the Hurst exponent in a number of stock market indices in periods of 2-4 years before significant drawdowns (crashes) such as occurred in October 1987 and March 2000.

\section{C. “TiPping Point” R1-INFORMATION COMPLEXITY ThRESHOLD}

Grossman and Stiglitz (1980) argue that if information gathering is costly, a competitive Walrasian market (our Triple Point; i.e., price equals supply and demand) does not always remain in equilibrium. Moreover, they show that when EMH is true and information is costly, competitive markets break down. Informed traders realize that they can stop paying for information and still do as well as uninformed traders. Therefore, having some fraction of informed traders does not necessarily produce equilibrium. Having no one informed is not equilibrium either, if each trader thinks that there are profits to be made from becoming informed.

Following Grossman and Stiglitz, we do not reject EMH but do wish to extend it to fit conditions when information is complex; i.e., costly and/or problematic with respect to market analysis. If information complexity increases, analysis becomes more costly and, hence, imitation in trading (herding) is more desirable, if not optimal, because it lowers costs. If the noise increases, information ambiguity prevails and the market is pervaded by uncertainty; efficient information processing and probabilistic decision-making becomes more difficult.

The high variability (volatility) of stock market returns is a signature of collective phenomena such as imitation or "herd" behavior. A quantitative link between bursts of volatility and herd behavior can be established through examination of order flows that display the aggregation of individual demands independent of the mechanism of herding - whether it is a sequential information cascade or random formation of groups through clustered networks. Implicit in herding behavior is the slow consolidation of traders toward the same buy-sell rule-i.e., rulebased trading - which then leads to correlated behavior; a good recent example being the slow spread of knowledge about the Black-Scholes options-pricing model that was at the heart of Long-Term Capital Management's temporary success.

\section{INCREASING VolatiLITY PERSISTENCE BEYOND R1}

\section{Persistence: Bubble Build-up Beyond R1 to Critical Point}

In an environment of increased uncertainty, rational probabilistic decision-making is impeded and the bimodal demand function (Plerou et al., 2003) signals herding behavior. At a certain level of information complexity, or when the buy/sell rule of another trader or group of traders is leading to obvious financial gain, a trader usually resorts to the alternative of rule-based trading instead of behavior consistent with EMH. Rule-based trading, herding, and information cascading, etc., create complex networking (self-organization) among traders, which then leads to a PL in the ACF of absolute log returns (volatility) that can be detected in the market data with scale-invariant methodology. Figure 5 shows the results of wavelet decomposition of S\&P 500 daily prices. The Wavelet Power Spectrum shows the coefficient of correlation between the prices and "Morlet wavelets" ${ }^{14}$ at different scales. The Global wavelet is the sum of the coefficients at different scales. The slope of the Global wavelet measures the Hurst exponent:

\footnotetext{
${ }^{14}$ A Morlet wavelet is defined at http://en.wikipedia.org/wiki/Morlet_wavelet
} 


$$
H=\frac{(\text { slope }-1)}{2}
$$

\section{>>>Insert Figure 5 about here $<<<$}

Under such circumstances, noise trading that disrupts EMH behavior has increased impact because noise can disrupt the symmetry among demand/supply and thereby destabilize pricesi.e., disrupt Triple Point trading. Below the critical value of information complexity, the net demand is roughly zero; neither buying nor selling predominates, which agrees with the dynamic stability in the basin of attraction - our Triple Point of a normal efficient market at equilibrium. Above this critical noise tipping point, $R 1$, a bimodal distribution of buy and sell limit orders emerges with the two most probable values symmetrical around zero demand as reported by Plerou et al. (2003).

This empirical evidence of change in the net-demand distribution explains the frequent reversal of stock markets, which creates the oscillation of prices, as documented by Sornette (2003a,b). Sethi (1996) shows that if chartists control a significant portion of trading, destabilized prices may show a sequence of period-doubling bifurcations. In this regime, markets - as complex dynamical systems - exhibit oscillations showing log-periodic behavior as discovered empirically by Johansen and Sornette (1998) and Sornette et al. (1996), among others. The bimodal distribution of demand reported by Plerou et al. (2003) suggests oscillation of the market between negative and positive demand phases in our phase-transition model graph (Figure 1). The phase transition at this the Triple Point is related to abrupt changes in the trading volume, induced by liquidity constraints. The reversal frequency of market sentiment is related to the increasing hazard rate of crash producing log periodicity in price oscillations. In the bubble-build-up sequence, rational traders evaluate the increasing price trend and hazard rate and then adapt their speculative strategy accordingly. Sornette (2003a) describes the build-up of cooperative speculation, which usually translates into an accelerating rise of the market.

Since traders mostly act sequentially rather than concurrently, herd-like behavior easily materializes; this results from information "copying" and rule-based behaviors in place of the normal random flow of less noisy information that supports rational EMH trading at the Triple Point. This copying behavior (e.g., observing others' actions) is then sufficient to induce agents to ignore their private information in favor of following the crowd, which results in information cascades, which are increasing daily volatilities caused by increasingly correlated trader buy-sell behaviors. Information cascades can result from observations of the stock trading trends by other traders rather than their reliance on their personal (private) - and more likely independentinformation. Thus, each and every participant may make mistaken trading decisions by simply following the crowd. In the earlier stages of information cascades they are more fragile-it doesn't take more than a little bit of public information (or an unusual signal) to overturn a cascade. But, at some point there is a likelihood that what starts as an information cascade becomes, itself, more resilient such that only significant outside anomalies can disrupt it. Our objective is to give longer-term market resilience dominance over the idiosyncratic
resilience of a particular relatively short-term information cascade and bubble-build-up.

The foregoing is best illustrated as follows: In Figure 6 we show Sornette and Johansen's (2001) translation of the Hang-Seng stock chart from linear to log Y-axis. The line in the righthand graph shows the log-scaled upward trend - the market rises exponentially at an "average" rate of 13.6\%. In Figure 7 we show the same graph in larger scale, with the log-based-13.6\%- 
up-trend line shown in red. We have now bifurcated each period between a crash and following peak by the intersection of two lines: (1) the yellow line, which more or less parallels the red line and indicates the period of trading at the Triple Point via EMH (Hurst exponent $<1 / 2$ ); and (2) the steeper-angled pink line, which indicates the period of log-periodicity, persistence and Hurst exponent $>1 / 2$ ).

\section{$>>>$ Insert Figures 6 and 7 about here $<<<$}

When information complexity in a market breaks across the $R 1$ tipping point (bifurcation point), deviations from the Triple Point "fair" prices may not be readily and efficiently corrected, given the presence of large numbers of rule-based traders, which then sets off a bubble build-up. Participants in the market influence each other in their trading decisions. Independent rational decision-making gives way to noise, copying, and imitation; the independence and heterogeneity of agents that keeps the market in equilibrium is lost. Traders self-organize in larger and larger clusters; finally the traders' network synchronizes resulting in a crash. Sornette (2003a,b) describes this as order in the market when everybody has the same opinion "sell." LeBaron (2001) suggests that traders losing diverse buy/sell rules evolve to one dominant trading rule, a finding that also supports our hypothesis of synchronization. Grech and Pamula (2008) show that shortly before a crash a few of what they call "speculative" traders start abandoning the herd; as more begin to jump from the bubble, the period of log periodicity ends and a crash occurs.

\section{Internal vs. External Shocks}

Empirical evidence indicates that the volatility signatures of endogenous ${ }^{15}$ and exogenous shocks ${ }^{16}$ to a system differ in the relaxation time-i.e., the time it takes a stock-trading system to collapse/crash back from the Critical Point to the "Triple Point," where greed, risk, and noise are balanced to produce EMH-style trading behaviors. Based on a number of recent empirical studies (Sornette et. al., 2002, Cajueiro et al. 2009, Zunino et al. 2009), we suggest several measures to prevent self-organization in a market from bubbling up to the Critical Point via herding, connectivity, and imitation. If our resilience interventions are to minimize the longer-term effects of market crashes - such as the current "Great Recession"- - which result from slower, selforganizing endogenous process dynamics - it is critical that we create resilience against endogenous processes rather than attempt to prevent anomalies foreign to the U.S. stock-trading system - such as the Asian meltdown of 1987, the Russian bond default of 1998, the dot.com crash of 2000, or the current meltdowns in Dubai (2009) and Greece (2010) - though we worry about these impacts as well because of increasing global interconnectivity; e.g., what happened in Dubai and Greece circa 2009, 2010 affected markets worldwide.

"Relaxation time" characterizes the way a dynamical system returns to equilibrium after experiencing significant deviations. It may measure the time-dependent response of a system to external stimuli or collapse of a self-organizing system after reaching an unsustainable phase. In

\footnotetext{
${ }^{15}$ Endogenous shocks result from perturbations within a system that initially impact a few agents (employees and/or subsystems) but then, because of tension and connectivity, the perturbation spreads and, via emergent selforganization processes, the TIEs can then scale up to impact the entire system. But this bottom-up percolation process take time, which is why endogenous change within a dynamical system is usually slower than exogenously induced change; the latter can impact most or all of a system's elements at the same time.

${ }^{16}$ A good example of an exogenous shock is the collapse of Long-Term Capital Management in 1998, which was caused by Russia's freezing of the Ruble, its bank-system collapse, and defaulting on its bonds, which then caused an overnight collapse of stock markets worldwide (Lowenstein, 2000: 140-141).
} 
fact, once a system reaches the Critical Point the relaxation time (i.e., the time needed for the market to retreat back from the top of the bubble to EMH-style trading at the Triple Point) is much longer because the collapse of a self-organizing system creates larger volatility bursts over a longer period of time. Sornette et al. (2002) show that the rate of the relaxation pattern of endogenous shocks via self-organizing after a system reaches the Critical Point takes more time than relaxation after exogenous shocks set off by external events, even if they occur before the system reaches the Critical Point-i.e., the Minsky Moment.

This difference between exogenous and endogenous shocks results from the way that volatility relaxes to its EMH-based average value: Sornette et al. (2002) show that endogenous shocks in the form of small perturbations (such as brief news reports (i.e., TIEs) seen by some traders that are then slowly spread around the system via trader networks such that the system incrementally self-organizes into a bubble-build-up phase) have the cumulative effect of slowly creating the specific trajectory building up to a Minsky Moment (which may occur before or at the Critical Point). Peaks caused via endogenous shocks also show slower relaxation rates as they self-organize to unwind back down toward the Triple Point. In contrast, exogenous shocks - created by a single overwhelming external anomaly_have a more rapid build-up to the Minsky Moment as well as a faster relaxation rate afterward.

In discussing the search for a "narrative" to explain what he calls the "Great Recession," Yergin (2009) argues that the normal oscillation between "fear and greed" characterizing stock markets following EMH at the Triple Point was shifted in favor of greed by the historically low cost of risk i.e., the Fed's discount rate dropped down to $0.75 \%$ in November 2002 . Add to this, Fed Chairman Ben Bernanke's comment in his October 23, 2009 speech to the Board of Governors of the Federal Reserve System:

The extraordinary pressure on financial firms last fall underscored how profoundly interconnected firms and markets are in our complex, global financial system

The "fear, greed, risk" dynamics of single human traders now interact among thousands of traders across a vast strongly-interconnected global financial system. Bernanke ends his speech by calling on Congress to legislate supervision capable of regulating vast complex interconnected systems rather than just individual CEOs, Boards, or Banks. While individual banks failed, it was global complex-system failure that caused the Great Recession, not "individual agents"-whether persons or banks. At the Triple Point isolated, rational, individual behavior rules the day; but as a market progresses toward a Minsky Moment, connectivity and scalability dynamics increasingly dominate to produce the extreme outcome at the Critical Point - a historically significant market crash.

To return to our earlier mention of Per Bak's sandpile avalanches, the tension basis of sand cascades from small to large is obvious in stock trading-"fear and greed." The connectivity of sand grains is what Bernanke points to: profound interconnectivity of firms throughout the global financial system. We don't deny that resilience engineering in many ways has to bear down on individual CEOs, Boards, and Banks. But, resilience engineering is meaningless if it doesn't produce global-system resilience. Bernanke stresses both individual and system in his speech. We try to deal with both as well. 


\section{BUILDING RESILIENCE}

We agree: The "magic of free markets" as Yergin (2009) calls it, should not be eradicated, as the French seem to prefer. At the Triple Point, and for some distance out toward Minsky Moments, the free market mantra should dominate. But as greed and connectivity begin to take the upper hand-i.e., once the $R 1$ tipping point is reached-resilience engineering needs to take hold to combat the formulas of financial engineering and slowly strengthen until the global system falls back below the $R 1$ tipping point - to safety and sanity. In short, free markets should be free to "resiliate" freely and without lobbying effects.

All of the resilience-engineering options we suggest below should be automatically activated once the tipping point is crossed. Needless to say, activation may be automatic or dependent on timely human decisions by regulatory and/or political entities. Information Disclosure (see below) should be as automatic as possible. Our position is that as many resilience interventions as possible should be automatically imposed (with possible amelioration later, if judged appropriate) - they should be protected against lobbying efforts and other ways of manipulating the judgments of regulating entities.

While we agree with Lord Turner (Britain's chief financial regulator) that special regulatory powers by what he terms a "macro-prudential committee," are needed to "prevent asset price bubbles" (Giles, 2010), we see the need to change his call for it to meet "twice a year...with power to pull a macro-prudential lever...if appropriate." We favor automatic imposition of the "levers" with power given to the "committee" to negate or alter them some time later if other lingering conditions warrant such action. Our principle is that formulaic automaticity comes first, with judgments imposed by (political) regulators coming later if further negative financial circumstances justify.

But is global system resilience engineering impossible? We wonder. Most nations don't like the idea of being regulated by other nations; witness the difficulties in dealing with global warming and nuclear weapons. Nobel Laureate James Tobin introduced his "Tobin Tax" on global currency exchange in 1978, but it has never taken hold even though there have been many strong advocacies in favor of it. ${ }^{17}$

We offer various preliminary suggestions about automatic, formula-based interventions below. Note that while we use the term "formulaic automaticity" just above, we do not go so far as to set forth specific formulas - this we leave to more technically trained financial resilience engineers. Most of the "formulas" we propose, that should be activated at the $R 1$ tipping point, are often not much more that simple ratios between increasing risk of some kind and increasing upfront cost to banks in the form of taxes on bonuses, reserve requirements, diminished risktaking, and so on.

We compartmentalize our resilience interventions into Information Disclosure, Individual Agents, Glass-Steagall related, Systemic Interconnectivities, and Other. Analogous to people driving cars, we divide "Individual Agents" into Reckless Endangerment (reckless financial engineering given easily available knowledge) and Insurance (protection against unexpected

\footnotetext{
${ }^{17}$ For a quick review and comment on the recent rash of news stories about the Tobin tax following Lord Turner's comment about whether London is too big to be "socially useful," see McKelvey, 2010.
} 
anomalies given increased risk, leverage, use of mortgage-backs, securitization packages, etc.). Overall, you can see that our Resilience Engineering reduces to two broad categories:

1. Use of increased information, in as many ways as possible, to reduce noise in favor of improved, more reliable information, so that traders feel it is safe to retreat back toward the EMH at the Triple Point; and

2. Various ways in which trading activities are gradually and/or severely restricted and/or various kinds of insurance called for once the system crosses the $R 1$ tipping point (as indicated by the Hurst exponent).

\section{A. RESILIENCE VIA INFORMATION DISCLOSURE:}

In this Section we build on the idea that "noise" in balanced EMH trading is really random information. But if new or relevant information is expensive, it becomes difficult for it to readily play its role as noise in EMH trading. We begin with a list of resilience-fostering information disclosures.

1. General: Any kind of increased information disclosure about bubble-build-up indications could hasten the likelihood that traders will retreat back from rule-based herd trading back to Triple Point trading;

2. Resilience "engineering" virtually by definition, has to use formulas to beat formulas; therefore "counter formulas" need to be invented and imposed; needless to say, relevant info is essential;

3. Any kind of info that helps uncover the $R 1$ tipping point;

4. Kinds of information that would disrupt/reduce trader-homogeneity and, thus, bolster efficientmarket trading;

5. Information that helps regulatory entities define conditions and causes of reckless endangerment;

6. The International Accounting Standards Board is already proposing that banks report estimated losses on their loans early on rather than waiting till they occur (Sanderson \& Hughes, 2009);

7. Information relevant to mitigating endogenous shocks;

a. Calls for information about events similar to the TIEs and spirals we highlight in the 34 years leading up to the 2007 liquidity crisis;

b. Makes easier comparisons of future events to those we have highlighted from the past 34 years.

8. Tracking of questionable management, Board Director interlocks, M\&A mistakes, Ponzi-use of bonuses to inappropriately motivate unacceptable levels of risk taking, as Bernanke calls for;

9. More attention to the tracking, control, and possible legislation to deal with "horizontal connectivity" across firms and across nations - as Bernanke calls for - as opposed to just watching and regulating "vertically" within individual firms.

10. Information suggesting that the end of the PL-identified trend is approaching; as is suggested by the research of Grech and Pamula (2008).

When information becomes costly, markets may not expeditiously be able to restore equilibrium - the benefits and seeming lower risk of joining the herd are cheaper and seem less risky than paying the cost of obtaining more valid information. Deviation from fair prices persists and returns are no longer described by normal distributions. PL dynamics are set off at the noise/information complexity tipping point, $R$ 1. It takes cheap and pretty much random information - i.e., inexpensive noisy information to keep systems in, or bring them back to the Triple Point's EMH trading. 
In equilibrium, stock market information is freely available and quickly incorporated in stock prices. Stock prices follow Brownian motion and volatility; the indicating Hurst exponent is 0.5. There is no long memory in the volatility, i.e. volatility autocorrelation function (ACF) shows exponential decay, a log/linear plot falls on an approximate straight line, which means the ACF has a characteristic scale - it is not scale invariant.

As the information becomes more complex, it requires more expensive processing or training to understand new asset pricing techniques, e.g., new derivatives, imitation, and rule based trading become optimal. Plerou et al. (2003) define this as a threshold-level of noise in the market that leads to bimodal demand distribution. They provide empirical evidence of two-phase behavior by financial markets, i.e., normal equilibrium and out-of-equilibrium markets.

Supported by their empirical results analyzing the probability distribution of demand conditioned on noise intensity, they argue the existence of a critical level of noise above which two highlyprobable values emerge. These values are symmetrical around zero demand and reveal excess demand and excess supply. A market breaks through $R l$ level (noise trading exceeds information trading) when information is costly and traders resort to imitation. Herding leads to bifurcation detected in the bimodal demand function. Traders' communication and increased level of imitation leads to gradual loss of heterogeneity and when one dominant trading rule prevails market crashes (LeBaron, 2001).

Near the Critical Point the autocorrelation function indicates long memory in the volatility, i.e. PLs, which suggests feedback processes and interdependence among traders, an increasing level of imitation, and loss of heterogeneity. One dominant trading rule evolves and at the Critical Point, because of some outside imposing anomaly, all traders have the same opinion "sell." Rule-based trading dominates the market and a continuous drawdown of prices follows.

\section{B. RESILIENCE ENGINEERING AgAINST INDIVIDUAL AgENTS (TRADERS, BANKS):}

In this Section we suggest a number of resilience interventions applied to individuals and banks, that are instigated once trading volatilities increase past the $R 1$ tipping point. There are many possible interventions. We end the Section with a focus on a few more obvious ratios that seem less prone to gaming.

1. Reckless Endangerment: (e.g., in the U.S., given that it was common knowledge that: the Fed. discount rate was $1.25 \%$ in December 2001 and $0.75 \%$ in November 2002 and would have to rise to protect against inflation; teaser loans lasted five years; and people could "buy" homes without declaring income or credit score; therefore we define leveraging mortgage-backs at 10, 20, 30, 40, and even up to 50 to 1 (in Europe) as demonstrable reckless endangerment). For the most part the Fed can define "recklessness" well in advance since some kinds of investment behaviors are well known in advance to be fraught with high risk. Given this:

a. All further risk-taking is gradually reduced automatically and progressively ${ }^{18}$ by formulaic resilience interventions against choiceful financial engineering activities as the bubble progresses, until risk is fully balanced by valid assets or compensation.

b. All bonuses, salaries, and other bank equities are essentially put in escrow (in a government-held account) until appropriate balance is achieved; Bernanke states that "compensation practices...have led to misaligned incentives and excessive risk-taking.... The Federal Reserve is working to ensure

\footnotetext{
${ }^{18}$ Our use of the term "progressive" comes from its use in progressive income taxes; the higher the income, the higher the tax. Our "progressive" interventions become stronger as the bubble progresses away from $R 1$
} 
that compensation packages appropriately tie rewards to long-term performance and do not create undue risk..." (Labaton, 2009).

c. As much early warning by the regulatory entity(ies) as is possible is to be given so that all bank parties can start taking appropriate progressive action;

d. Executives, financial engineers and traders directly responsible for recklessness should lose their positions and be held liable for returning all bonuses dating back to the start of reckless judgments; direct superiors up to CEOs should also be fired (see Record, 2010).

e. Reckless endangerment becomes more relevant when banks participate in an "asset-price bubble" of the kind that Mishkin (2009) calls "a credit boom bubble" based on willful bank-caused (endogenous) high-leveraged lending practices based on questionable assets like mortgage-backs, as opposed to a "pure irrational exuberance bubble" (like the one based on dot.com stocks in the late 1990s) which was exogenous. By the SEC's count, this includes "securitized—or repackaged - pools of subprime mortgages" and re-securitized collateralized debt obligations (CDOs) backed by mortgages and other loans held by a bank. Why these? By $2007 \sim 74 \%$ of CDOs had failed and $\sim 86 \%$ of bonds backed by mortgage-backed securities had failed (Chung, 2010).

2. Insurance: (like any insurance, resilience insurance is defined by both the total financial liability and some measure of the likelihood of "crash-causing" anomalies). As asset liability and risk of anomalies increase, insurance costs are increased:

a. Designated "hi-risk" banks and other players (like AIG, Fanny Mae, Freddie Mac) would pay into an insurance fund; payments would be made before bonuses are paid out; payments would be progressive, starting at the $R 1$ tipping point; after some time they would amount to some percentage of the prior year's bonus pool, say $90 \%$ (what the highest income tax used to be in the U.S.);

b. Prime Minister Gordon Brown \& Chancellor Alistair Darling, at the G20 Finance Ministers' meeting at St. Andrew's, Scotland, once again brought up the "Tobin tax" (recently called the "casino tax") (Aitken, 2009; Eaglesham et al., 2009); it would be applied to all financial transactions. Our view is that, as a resilience measure, this tax would be introduced at the $R 1$ tipping point and then increased from miniscule to substantial. But the U.S., Canada, \& IMF dismissed it immediately. Ours is a compromise: it wouldn't apply till after $R 1$ : our use of " $R 1$ timed introduction of insurance to cover "reckless endangerment," thus, could keep both sides happy;

c. Raise borrowing costs for "hi-risk" taking banks; accounts to Yergin's "easy credit," which is at the base of "Shilleresque" bubbles in real estate, energy," etc. McCormack (2009) suggests that the best solution would be "a tax on short-term debt, especially short-term debt of financial institutions"; we add in the term, progressive;

d. What The Economist (2009c) calls "capital ratios" (also called "living wills" or "catastrophe insurance") are imposed to penalize risky behaviors;

e. Mervyn King suggests that when the State acts as "lender of last resort" it would be appropriate to "impose a windfall tax on bank profits or a 'Tobin tax' on transactions" (The Economist, 2009c);

f. President Obama is proposing a "bank fee" based "on the amount of a financial firm's liabilities;" the fee increases progressively as risk increase

g. The FDIC takes the position of wanting a depositors insurance fee levied against bank compensation plans that promulgate hi-risk strategies while paying out bonuses (pretty much like Ponzi schemes) well before knowing whether the risk-taking produced profits or losses (Chung \& Guerrera, 2010);

h. Forced reduction in leverage; accounts to Yergin's "too much leverage"; based on a ratio to a bank's secure assets, or increased insurance against the leverage; 
i. Limits on short selling (deal with several kinds); or increased insurance to cover down-side risks and costs; thus at $R 1$ :

(1) Short selling with no assets involved is stopped; Computerized short selling is stopped;

(2) The next worst type of short selling, and so on, are stopped as the bubble grows;

(3) Though not necessarily short selling, we also call for growing limits on hi-speed autonomous computerized trading after $R 1$ since the tremendous volume-largely unsupervised — can have significant market impacts;

j. Shadow operations by individual hedge funds have to be disclosed at the tipping point; insurance costs are then progressively applied;

k. More attention focused on giving shareholders more relevant info and more responsibility/authority/control over CEO Ponzi bonus-giving, inordinate risk-taking, and behaviors such as Ken Lewis's at BofA when he reduced shareholder value by buying Merrill Lynch after the latter had doled out \$billions in bonuses to traders who engineered incredible failures (ML paid out more in bonuses than it earned in 2008! — which BofA shareholders paid for). After R1, shareholders have progressively enhanced voting rights on increasing risk, leverage, etc.

1. All bonuses, anywhere, should be subject to progressive income tax, period.

\section{Reinstating Glass-Steagall? Not Needed if " $R 1$ " is Followed:}

1. If "reckless" banks are "too big to fail," some propose reinstating Glass-Steagall (e.g. Senators McCain \& Cantwell, among others) (Pozen, 2010);

2. Simon Johnson (an MIT professor and former economist with the IMF), suggests creating "five mini-Goldmans" (Task, 2010), with bank size limited by some ratio to GDP;

3. While gradual imposition of an updated Glass-Steagall Act could be imposed, banks would not be split up [as Mervyn King, Governor, Bank of England proposes (Thomas, 2010)], but would more and more be divided into a "good bank" and a "bad bank" - and we would put the latter put into the "reckless endangerment" category;

4. Most recently, the Obama Administration, via Paul Volcker (former Fed Chairman), suggested what is now called the "Volcker Rule"-i.e., "deposit-taking banks would not be able to engage in proprietary trading, or to own hedge funds or private equity firms" (Gapper, 2010). Volcker holds that "prohibiting commercial banks from some high-risk trades should be an essential component of broader financial regulations and would cut back on institutions deemed "too big to fail," (Associated Press, 2010). Again, we don't believe up-front separating banks is necessary; see also Lackritz (2010). We suggest progressive resilience interventions imposed after $R 1$;

5. Nicholas Brady (2010; former US Treasure Secretary) makes the needed split between "depositbased banks" vs. the "shadow banking system" engaged in speculative trading and almost overtly reckless endangerment. He thinks it is "delusional" to put faith in formulas; we think the recent record shows it is equally delusional to put faith in politicians controlling regulators; we believe only automatic interventions via imposing "resilience formulas" designed to take hold at the $R 1$ tipping point, at the speed at which financial engineering trading decisions are made (i.e., within microseconds), will keep modern risk taking in timely check. In short: It takes resilience engineering to beat financial engineering;

6. Our position is that the Glass-Steagall, or five miniGoldmans, or good bank/bad bank solutions are not required if our "formulaic resilience engineering application" approach is consistently and expeditiously applied against risks based on financial engineering and reckless endangerment; and imposed minimally at the $R 1$ tipping point and then increasing automatically and progressively with respect to risk and reckless endangerment as bubble-build-up progresses

\section{Systemic Interconnectivities: Applied After R1:}


1. Progressive limits on securitization repackaging (systemic since they are sold to other banks, sold worldwide, etc.);

2. Progressive limits on non-cash securitization repackaging (systemic, as above);

3. Tracking the contagion of financial engineering formulas; when their contagion level reaches a specific level of trader homogeneity, insurance costs against systemic collapse need to be imposed, as Bernanke calls for;

4. Tracking growth and, then, operations of shadow trading by hidden, "private" stock exchanges; these come under intervention at the tipping point;

5. Make markets more susceptible to transient international changes; as the likelihood of particular international changes - e.g., bond defaults, govt. failures, etc.- - become more likely, traders \& firms at risk are required to build-up insurance, reduce leverage, restrict short selling, etc.;

6. Resilience against combinations: We already know that levels of indebtedness connected to exceedingly low interest rates (especially in real estate now that we have mortgage-backs), coupled to interest-rate increases to fend off inflation, coupled with the use of teaser loans; their end-dates coupled to increased variable interest rates, etc., set off the combination of tactics that began the Great Recession; the listed coupled ingredients need to be tracked carefully so as to avoid the obvious again.

\section{Other:}

1. We agree with Jacek Rostowski (2010; Finance Minister of Poland) that when interest rates are extremely low - as they were in 2001-2003 when the bubble started - they surely should be automatically raised once $R 1$ is reached; or even higher if they have already been raised off their lows. The so-called "Greenspan put," which kept interest rates very low longer than necessary is to be avoided like the plague. This approach is backed up by Tom Hoenig (President of the Kansas City Fed; Guha, 2010);

2. Going back to our description of the "liquidity crisis example" in Section III, resilience engineering restrictions in both Reckless Endangerment and Insurance categories could have been taken anywhere along the progression from 1973 to 2007; we try to make it obvious just how many ways and stages that scalability dynamics became operative well before 2007, that call for resilience interventions - but not before the $R 1$ tipping point;

3. All the foregoing formulaic resilience interventions would zero back down as the as the system reverts back below the $R 1$ tipping point and presumably before the Triple Point; i.e., when the Hurst exponent, $H$, goes below $1 / 2$. This would happen before the Triple Point is reached.

While we believe our instigation of formulaic resilience engineering interventions after the $R 1$ tipping point is better than those currently being discussed (many of which we have already alluded to in our earlier discussion of specifics), there are still two problems to be worried about: (1) How to prevent financial engineers from gaming the system (like people constantly finding loopholes in tax regulations)? And (2) How many formulas should be initiated at $R 1$ and how complicated should they be designed?

First, outwitting the system: Even its Chairman, Christopher Cox, admits the SEC's Wall Street regulation methods were "fundamentally flawed from the beginning" (Labaton, 2008; see also Kauffman, 2008). Over the past couple of years the SEC has been pummeled for its (1) failure to take early note of Madoff's Ponzi scheme, and (2) its inability to hire staff competent to understand, let alone regulate, financial engineering. The key issue in the latter, is: Why would talented financial engineers who can make \$\$millions in investment banking be willing to settle for making \$\$thousands working for the SEC? And, if this is indeed the case, which we think it is: How is the SEC or the Fed going to be able to outwit the gaming of the financial engineers in New York City or in hedge funds scattered around the world? 
We suspect there are some early-retired wealthy financial engineers who would simply enjoy working for less and would actually have fun trying to out-game their previous competitorsthough we admit there is some risk that they might secretly work to benefit their quant cronies rather than be totally neutral (e.g., some would argue that Hank Paulson did nothing more with TARP and AIG than protect his former firm, Goldman Sachs). There are probably some Cal Tech $^{19}$ and MIT grads who have more interest in working for the greater good than simply trying to make money. Yes, we think people like this exist! And, the simpler the formulas, the easier the task of designing them. Actually, a likely candidate may very well be Gary Gensler. He started at Goldman Sachs, earned a fortune by age 30, and then moved to the Treasury Dept. in the late 1990s, where he became head of the Commodity Futures Trading Commission. Gensler has become a strong advocate for tough regulations. "Like San Francisco after the earthquake, we had a calamity, and now we need new building codes" (Bowley, 2010).

Second, the formulas: The second way to combat is via the design of the formulas and, to the extent possible, making them secretly and randomly changeable/applicable so that even if gaming takes place it is more like roulette than playing against a relatively unchanging and very public tax code. Needless to say, we don't try to design them here. Boiled down, we suggest an initial focus on simple ratios connected to numbers based on the size of things easily identified after $R 1$ tipping point is passed; like, for example:

1. A progressive income tax, and/or an increasing percentage of bonuses and bank equities are put in temporary escrow; time in escrow increases in direct ratio with (risk $\times$ leverage) of all loans based on "non-secure assets."

2. The more that bank decisions pertain to higher (non-secure asset-based risk $\times$ leverage), the more points an executive accumulates toward automatic loss of job.

3. Banks defined as "hi-risk," based on (non-secure asset-based risk $\times$ leverage), pay into an insurance fund before any bonuses or dividends can be paid out.

4. A progressive Tobin-like tax is imposed on all financial transactions (may be difficult to pull off, but would be ideal if it were to happen).

5. Banks defined as hi-risk would face progressively increasing "risk-vulnerability" tax on the amount borrowed as (non-secure asset-based risk $\times$ leverage) increases.

6. As any kind of leverage is increased, a progressive bank fee is imposed.

7. As the ratio of (non-secure asset-based risk $\times$ leverage) increases relative to secure assets, banks progressively pay increasing amounts into an insurance fund.

8. As the ratio of (non-secure asset-based risk $\times$ leverage) increases relative to secure assets, depositor insurance fees are progressively increased, short selling, shadow operations, and non-human computerized trading is are progressively limited.

9. All of the above are increased as their ratio to non-secure-asset based loan securitizations increases.

10. As combinations of very low interest rates coupled with teaser loans appear, loans based on nonsecure assets are progressively reduced.

11. Interest rates on loans based on any kind of asset are automatically and progressively raised as volatilities increase after $R 1$.

12. Bonuses progressively approaching the equivalent of bonuses given out by banks would be offered to whistle blowers. Yes, they might wait till risk is higher, but at the same time they risk that some other whistle blower will beat them to the punch!

\footnotetext{
${ }^{19}$ The Economist (2010; p. 5 of Special Report) says that in 2007 some $25 \%$ of Cal Tech grads went into finance.
} 
13. Put simply: As bank risk and bonuses increase they make progressively increasing payments into a risk-protection fund; this fund is also progressively taxed as the bubble progresses beyond $R 1$.

\section{CONCLUSION}

A brief review in Section II of the Hollnagel et al. book, Resilience Engineering: Concepts and Precepts (2006) supports our development of resilience engineering in the context of complexity dynamics. In Section III we introduce econophysics, which dates back to Mandelbrot's works of 1963a,b and 1982, among many others, and more recently works by Schroeder (1991), West and Deering (1995), Mantegna \& Stanley (2000), Vasconcelos (2004), and Newman (2005). Gell-Mann (1988) emphasizes the search for SFTs - simple theories that explain complex, multi-level phenomena. We also define key elements of scalability, specifically fractal structures, power laws, and SFTs. Econophysics research covers such topics as returns in financial markets, economic shocks and growth rates, firm size and growth rates, income and wealth, city sizes, scientific discoveries, networks, and most recently stock market volatility dynamics, detecting stock market bubbles and predicting crashes.

In Section III we go back to 1973 to trace out key financial inventions-such as derivatives, computer-based financial engineering, and mortgage-backed securities - and other events that appear as precursors to, and eventually causes of, the 2007 liquidity crisis and the crash of the Dow Jones stock-trading index from its high of 14,198 down to 6,469. In our recounting of the history of events leading into the 2007 crisis and subsequent DJSI crash, we identify the "tiny initiating events" (Holland, 1995, 2002) that set off what Hyman Minsky $(1982,1986)$ called "positive feedback" processes - and what we now use a broader set of scale-free theories to explain. While there have been many small crashes, and several world-wide crashes since 1973, we focus only on events leading up to the 2007 crisis. In this regard, we note one of our scalefree theories - "combination theory" (Newman, 2005) - explains why any single scale-free dynamic did not set off the liquidity crisis; no single one of them was strong enough. Their interactive combination building up over time, however, did in fact result in the post-2007 Great Recession. Herding behavior and Minsky Moments are defined in Section IV.

In Sections V and VI we further develop one of the most recent ideas centering on the use of econophysics: the use of the 'volatility autocorrelation function', Hurst exponent, $H$, and power laws. We develop in greater detail a theory building on Sornette et al.'s empirical work (Yan, Woodard \& Sornette, 2010) that underlies his and our use of log periodicity and $H>1 / 2$ to indicate the positioning of our ' $R 1$ ' tipping-point indicator. This allows us to identify the tipping point between the random trader behavior at what Yalamova and McKelvey (2009) call the Triple Point [where greed, risk, and noise are balanced à la Bachelier's random walk of stock markets (PhD dissertation in 1900) and Fama's EMH (1970)] and the beginning of herding-style trading — which dates back to Henri Poincaré (1914) — that instigates bubble-build-ups toward a market crash at the Critical Point.

We offer a cautionary note, however, since the research basis of our $R 1$ concept, has various rough edges needing further development. Our view on this, however, is that even if only half of the $>10 \%$ market crashes are predicted early on by our $R 1$, the reduction of the costs imposed on the MANY paying the societal cost stemming from Greenspan's 'irrational exuberance' by the FEW who make \$ \$billions before the crash is well worth it. And, in the remaining instances 
where $R 1$ is, perhaps unnecessarily imposed, the resilience bolsters may very well be expeditious anyway.

In Sections VII we develop a set of formulaic resilience engineering interventions to be applied at the R1 tipping point to offset "irrational exuberance" by financial engineers and all their formulas. We offer a wide variety of $\sim 40$ different resilience interventions. We begin by suggesting 10 bearing on basic measures for improving Information Disclosure interventionsthe better is information quality and relevance, the more relevant and timely is resilience. As our review of the build-up to the 2007 liquidity crisis shows, relevant information is available: One just has to know better what to look for. Then we point out that, like driving a car, there are obvious cases of choiceful Reckless Endangerment -5 resilience interventions here - as well as 12 interventions to build-up Insurance against unpredictable anomalies. Then, because modern financial markets are so Systemically Interconnected around the globe, we offer 6 resilience interventions that become relevant as interconnectivity builds. Finally, and most importantly, we believe that the only viable solution, given the computer-based speed at which financial engineering quant formulas operate, is to set up resilience formulas that automatically take hold at $R 1$ - only resilience engineering formulas can beat financial engineering formulas.

Financial engineering resilience interventions have to be imposed as early as possible in the transition from random-walk-EMH (Bachelier, 1914; Fama, 1970) trader behavior at the Triple Point to bubble-build-ups based on trader herding behavior leading up to the Critical Point (i.e., stock market crash; Yalamova \& McKelvey, 2009) as is possible, but not too early. The key question is: How appropriately early we can get resilience dynamics introduced to offset the various dynamics underlying the build-up toward the Critical Point? A recent study by Wasden (2010) finds that two-thirds of the cues pointing to the failure of Bear Stearns and Lehman Brothers were after the fact of their failure, with the result that whatever interventions that regulators or politicians came up with had no chance of being preventive.

There are now many books and vastly more articles and newspaper stories calling for heightened regulation. Some of this is summarized in The Economist's report on financial risk (2010). However, there is no evidence that any currently proposed solution does what our approach does: leave the banking system as currently regulated-i.e., relatively unregulated — as long as it stays pretty much at the Triple Point, which is to say, as long as it stays with balanced greed, risk, and uncertainty and behaves according to Bachelier's random walk and Fama's EMH. Our approach is more like progressive income tax: poor people pay no tax, but as people earn more income they pay progressively more tax. Our resilience interventions only apply after the $R 1$ tipping point is reached in stock price volatilities. They only start being imposed after EMH ceases to apply; they apply only if traders lose their heterogeneity, if herding behaviors start, if buy-sell rules become more similar, if bank and global connectivities multiply, ${ }^{20}$ and if the Hurst exponent indicates that a bubble-build-up toward a crash has begun.

All of the twelve examples we mention at the end of Section VII are easily reduced to formulas involving progressive bank-cost increases as risk increases, i.e., they are based on ratios involving readily identified risks taken against readily identifiably asset quality. We recognize that there is always the danger and temptation of banks attempting to hide risky actions. We argue, however, that hidden risk is easily measured as the ratio of bonuses offered relative to the

\footnotetext{
${ }^{20}$ At the time it was allowed to fail, Lehman Brothers was comprised of "nearly 3000 legal entities in dozens of countries" (The Economist, 2010; p. 15 of Special Report), with most under minimal, if any, regulation.
} 
total known assets of a bank. Either this is true or bonuses are given out without any kind of merit (risky or not), or they are based on hidden assets and shadow banking. Period. Banks should be held accountable no matter which alternative applies.

\section{REFERENCES}

Aitken, M. (2009). Chancellor's Plan for Tax on Banks Gets Shot Down at G20. Daily Record (Nov. 8), http://www.dailyrecord.co.uk/news/uk-world-news/2009/11/08/chancellor-s-plan-for-tax-on-banks-gets-shotdown-at-g20-86908-21806360/ (accessed Nov. 9, 2009).

Alvarez-Ramirez, J., Alvarez, J, Rodriguez, E. \& Fernandez-Anaya, G. (2008). Time-varying Hurst Exponent for US Stock Markets. Physica A, 387, 6159-6169.

Andriani, P. \& McKelvey, B. (2007). Beyond Gaussian Averages: Extending Organization Science to Extreme Events and Power Laws. Journal of International Business Studies, 38, 1212-1230.

Andriani, P. \& McKelvey, B. (2009). From Gaussian to Paretian Thinking: Causes and Implications of Power Laws in Organizations. Organization Science, 20, 1053-1071.

Andriani, P. \& McKelvey, B. (2010a). From Skew Distributions to Power-Law Science. In P. Allen, S. Maguire \& B. McKelvey (Eds.), Handbook of Complexity and Management. London: Sage.

Andriani, P. \& McKelvey, B. (2010b). Using Scale-free Theory from Complexity Science to Better Management Risk. Risk Management, An International Journal, 12, 54-82.

Arneodo, A., Muzy, J. \& Sornette, D. (1998). "Direct" Casual Cascade in the Stock market, European Physical Journal B, 2, 277-282.

Associated Press (2010). Volcker Calls for Commercial Bank Trading Limits. Forbes.com (Feb. 10), http://www.forbes.com/feeds/ap/2010/02/02/general-us-financial-overhaul_7323511.html (accessed Feb. 15, 2010).

Auerbach, F. (1913). Das Gesetz Der Bevolkerungskoncentration. Petermanns Geographische Mitteilungen, 59, $74-$ 76.

Axtell, R. L. (2001). Zipf Distribution of U.S. Firm Sizes. Science, 293, 1818-1820.

Bachelier, L. (1914). Le Jeu, la Chance et la Hasard. Paris: E. Flammarion.

Bak, P. (1996). How Nature Works: The Science of Self-organized Criticality. New York: Copernicus.

Bak, P., Tang, C. \& Wiesenfeld, K. (1987). Self-organized Criticality: An Explanation of 1/f Noise. Physical Review Letters, 381-384.

Baker, D. (2009). Plunder and Blunder: The Rise and Fall of the Bubble Economy. PoliPoint Press, Sausalito, CA.

Banerjee, A. V. (1992). A Simple Model of Herd Behavior. The Quarterly Journal of Economics 107, 797-817.

Barabási, A.-L. \& Bonabeau, E. (2003); Scale-free Networks. Scientific American, 288(May): 60-69.

Barabási, A.-L. (2002). Linked: The New Science of Networks. Cambridge, MA: Perseus.

Basili, M. \& Zappia, C. (2003) Probabilistic versus Non-probabilistic Decision Making: Savage, Shackle and Beyond. University of Siena Economics Working Paper No. 403.

Baskin, K. (2005). Complexity, Stories and Knowing. Emergence: Complexity \& Organization 7, 32-40.

Battiston, S. \& Catanzaro, M. (2004). Statistical Properties of Corporate Board and Director Networks. European Physical Journal B, 38, 345-352.

Batty, M., Carvalho, R., Hudson-Smith, A., Milton, R., Smith, D. \& Steadman, P. (2008). Scaling and allometry in the building geometries of Greater London. European Physical Journal B, 63, 303-314. 
Baum, J. A. C. \& McKelvey, B. (2006). Analysis of Extremes in Management Studies. In D. J. Ketchen, Jr. and D. D. Bergh (eds), Research Methodology in Strategy and Management, Vol. 3, pp. 123-196. Elsevier Ltd.

Bernanke, B. S. (2009). Financial Regulation and supervision after the Crisis: The Role of the Federal Reserve. Financial Times (Oct. 23). http://www.ft.com/cms/s/0/1f0e0df8-bfd2-11de-aed2-00144feab49a.html (accessed Oct. 24, 2009) (accessed Oct. 24, 2009).

Bettencourt, L. M. A., Lobo, J. \& West, G. B. (2008). Why are Large Cities Faster? Universal Scaling and Selfsimilarity in Urban Organization and Dynamics. European Physics Journal, 63, 285-293.

Bikhchandani, S., Hirshleifer, D. \& Welch, I. (1992). A Theory of Fads, Fashion, Custom, and Cultural Change as Informational Cascades. Journal of Political Economy 100, 992-1026.

Black, F. \& Scholes, M. (1973). The Pricing of Options and Corporate Liabilities. Journal of Political Economy, 81, 637-654.

Black, F. (1972). Capital Market Equilibrium with Restricted Borrowing. Journal of Business, 45, 444-455.

Blanchard, O. (1979). Speculative Bubbles, Crashes and Rational Expectations. Economic Letters, 3, 387-389

Blanchard, O. \& Watson, M. (1982). Bubbles, Rational Expectations and Financial Markets. In P. Wachtel (ed.), Crises in the Economic and Financial Structure, pp. 295-316. Lexington, MA, D. C. Heathland Co.

Blodget, H. (2008). Did Bear Stearns CEO Alan Schwartz lie on CNBC? Business Insider (March 19) http://www.businessinsider.com/2008/3/bear-stearns-bsc-did-ceo-alan-schwartz-lie-on-cnbc- (accessed Oct. 25, 2009).

Bollerslev, T. (1986). Generalized autoregressive conditional heteroscedasticity. Journal of Econometrics 31, $307-$ 327.

Bowley, G. (2010). Goldman Deal-Maker Now Advocates Regulation. New York Times (March 11) http://www.nytimes.com/2010/03/11/business/11cftc.html?ref=business

Brady, N. F. (2010). Refocus the Regulatory Debate on Essentials. Financial Times (Jan. 4), http://www.ft.com/cms/s/0/3e8f914e-f969-11de-8085-00144feab49a.html (accessed Feb. 15, 2010).

Brock, W. A. (2000). Some Santa Fe Scenery. D. Colander, ed. The Complexity Vision and the Teaching of Economics. Cheltenham, UK: Edward Elgar, pp. 29-49.

Brunnermeier, M. K. (2001). Asset Pricing under Asymmetric Information: Bubbles, Crashes, Technical Analysis, and Herding. Oxford, UK: Oxford University Press.

Cajueiro, D. O. \& Tabak, B. M. (2004). The Hurst Exponent Over Time: Testing the Assertion that Emerging Markets are Becoming More Efficient. Physica A, 336, 521-537.

Cajueiro, D.O., Tabak, B. M. \& Werneck, F.K. (2009). Can we predict crashes? The case of the Brazilian stock market, Physica A, 388, 1603-1609.

Canning, D., Amaral, L. A. N., Lee, Y., Meyer, M. \& Stanley, H. E. (1998). A Power Law for Scaliong the Volatility of GDP Growth Rates with Country Size. Economics Letters, 60, 335-341.

Chatterjee, A., Yarlagadda, S. \& Charkrabarti, B. K. (Eds.) (2005). Econophysics of Wealth Distributions. Milan: Springer.

Chmiel, A. M., Sienkiewicz, J., Suchecki, K. \& Holyst, J. A. (2007). Networks of Companies and Branches in Poland. Physica A, 383, 134-138.

Chou, L. \& Keane, C. (2009). How the Internet works: Inspired by Per Bak. Term paper, HCS Complexity Course, Winter Quarter, UCLAAnderson School of Management, Los Angeles, CA.

Chung, J. \& Guerrera, F. (2010). FDIC Eyes Linking Levies to Bank Pay. Financial Times (Jan 7), http://www.ft.com/cms/s/0/1b733a94-fb26-11de-94d8-00144feab49a.html (accessed Feb. 15, 2010).

Chung, J. (2010). Regulator has Sights Trained on Bank Sales Practices. Financial Times (Jan. 15), http://www.ft.com/cms/s/0/8a3910f8-0174-11df-8c54-00144feabdc0.html (accessed Feb. 15, 2010). 
Cirillo, P. \& Husler, J. (2009). On the Upper Tail of Italian Firms' Size Distribution. Physica A, 388, 1546-1554.

Clauset, A., C. Shalizi, R. \& Newman, M. E. J. (2007). Power-law Distributions in Empirical Data. ArXiv:0706.1062v1 [physics.data-an] June.

Clementi, F. \& Gallegati, M. (2005). Power Law Tails in the Italian Personal Income Distribution. Physica A, 350, $427-438$.

Cohan, W. D. (2009). House of Cards: A Tale of Hubris and Wretched Excess on Wall Street. New York: Doubleday.

Cooper, G. (2008). The Origin of Financial Crises. New York, Vintage Books.

Di Guilmi, C., Gaffeo, E. \& Gallegati, M. (2003). Power Law Scaling in the World Income Distribution. Economics Bulletin, 15(6), 1-7.

Drăgulescu, A. A. \& Yakovenko, V. M. (2001). Exponential and Power-law Probability Distributions of Wealth and Income in the United Kingdom and the United States. Physica A, 299, 213-221.

Du, G. \& Ning, X. (2008). Multifractal Properties of Chinese Stock Market in Shanghai. Physica A, 387, 261-260.

Eaglesham, J., Giles, C. \& Hollinger, P. (2009). Brown Retreats from Tobin Tax Proposal after US-led Backlash. Financial Times, (Nov. 9): 1.

Ellis, C. \& Hudson, C. (2007). Scale-adjusted Volatility and the Dow Jones Index. Physica A, 378, 374-386.

Engle, R. F. (1982).Autoregressive Conditional Heteroscedasticity with Estimates of Variance of United Kingdom Inflation. Econometrica, 50, 987-1008.

Engle, R. F. \& Bollerslev, T. (1986). Modeling the Persistence of Conditional Variances. Econometric Reviews, 5, 150.

Eom, C., Choi, S., Oh, G. \& Jung, W.-S. (2008). Hurst Exponent and Prediction Based on Weak-form Efficient Market Hypothesis of Stock Markets. Physica A, 387, 4630-4636.

Epstein, J. M. \& Axtell, R. (1996). Growing Artificial Societies. Cambridge, MA: MIT Press.

Fama, E. F. (1970). Efficient Capital Markets: A Review of Theory and Empirical Work. Journal of Finance, 21, 383-417.

Fama, E. F. (1998). Market Efficiency, Long-term Returns, and Behavioral Finance, Journal of Financial Economics, 49, 283-306.

Fama, E. F. (1965). Random Walks in Stock Market Prices. Financial Analysts Journal, 21(5), 55-59.

Farmer, J. D. \& Joshi, S. (2002). The Price Dynamics of Common Trading Strategies. Journal of Economic Behavior and Organization, 49, 149-171.

Foster, J. B. \& Magdoff, F. (2009). The Great Financial Crisis. New York, Monthly Review Press.

Fox, J. (2009). The Myth of the Rational Market. New York: HarperBusiness.

Gabaix, X. (1999). Zipf's Law for Cities: An Explanation. Quarterly Journal of Economics, 114, 739-767.

Gapper, J. (2010). Volcker has the Measure of the Banks. Financial Times (Jan. 27), http://www.ft.com/cms/s/0/f00aa3dc-0b7a-11df-8232-00144feabdc0.html (accessed Feb. 15, 2010).

Garmestani, A. S., Allen, C. R. \& Gallagher, C. M. (2008). Power laws, Discontinuities and Regional City Size Distributions. Journal of Economic Behavior \& Organization, 68, 209-216.

Gay, B. \& Dousset, B. (2005). Innovation and Network Structural Dynamics: Study of the Alliance Network of a Major Sector of the Biotechnology Industry. Research Policy, 34, 1457-1475.

Gell-Mann, M. (1988). The Concept of the Institute. In D. Pines (Ed.), Emerging Synthesis in Science, pp. 1-15. Boston, MA: Addison-Wesley.

Gell-Mann, M. (2002). What is Complexity? In A. Q. Curzio, and M. Fortis (Eds.), Complexity and Industrial Clusters, pp. 13-24. Heidelberg, Germany: Physica-Verlag. 
Gençay, R., Selçuk, F. \& Witcher, B. (2004). Asymmetry of Information Flow Between Volatilities Across Time Scales. Econometric Society: North American Winter Meetings No. 90, pp.35

Ghashghaie, S., Breymann, W., Peinke, J., Talkner, P. \& Dodge, Y. (1996). Turbulent Cascade in Foreign Exchange Markets. Nature, 381, 767-770..

Ghysels, E., Santa-Clara, P. \& Valkanov, R. (2005). There is a Risk-return Trade-off After All. Journal of Financial Economics, 76, 509-548.

Gilbert, M. (2010). Complicit: How Greed and Collusion Made the Credit Crisis Unstoppable. New York: Bloomberg Press.

Giles, C. (2010). Turner Calls for Powers to Deflate Asset Bubbles. Financial Times (Jan. 27), http://www.ft.com/cms/s/0/d2bf7a9c-0b4c-11df-9109-00144feabdc0.html (accessed Feb. 15, 2010).

Glaser, P. (2009). Fitness and Inequality in an Increasing-returns World. Term paper, Complexity Leadership course, Spring Quarter, UCLAAnderson School of Management, Los Angeles, CA.

Gopakrishnan, P., Plerou, V., Amaral, L. A. N., Meyer, M. \& Stanley, H. E. (1999). Scaling of the Distributions of fluctuations of Financial Market Indices. Physical Review E, 60, 5305-5316.

Grech, D. \& Mazur, Z. (2004). Can One Make a Crash Prediction in Finance Using the Local Hurst Exponent Idea? Physica A, 336, 133-145.

Grech, D. \& Pamula, G. (2008). The Local Hurst Exponent of the Financial Time Series in the Vicinity of Crashes on the Polish Stock Exchange Market. Physica A, 387, 4299-4308.

Greenspan, A. (1996). The Challenge of Central Banking in a Democratic Society. Remarks at the Annual Dinner and Francis Boyer Lecture of the American Enterprise Institute for Public Policy Research, Washington DC, December 5.

Grossman, S. J. \& Stiglitz, J. E. (1980). “On the Impossibility of Informationally Efficient Markets.” American Economic Review, 70, 393-408.

Guha, K. (2010). Federal Reserve Warned on Interest Rates. Financial Times (Jan. 8) http://www.ft.com/cms/s/0/74c23e0c-fbe8-11de-9c29-00144feab49a.html (accessed Feb. 15, 2010).

Holland, J. H. (1995). Hidden Order: How Adaptation Builds Complexity, Reading, MA: Addison-Wesley.

Holland, J. H. (1998). Emergence: From Chaos to Order. Cambridge, MA: Perseus.

Holland, J. H. (2002). Complex Adaptive Systems and Spontaneous Emergence. In A. Q. Curzio, and M. Fortis (eds.), Complexity and Industrial Clusters, pp. 25-34. Heidelberg, Germany: Physica-Verlag.

Hollnagel, E., D. D. Woods, \& N. Leveson (Eds.) 2006.Resilience Engineering: Concepts and Precepts. Aldershot, Hampshire, UK: Ashgate.

Iansiti, M. \& Levien, R. (2004). Strategy as Ecology. Harvard Business Review, 82(3), 68-78.

Ishikawa, A. (2006). Pareto Index Induced from the Scale of Companies. Physica A, 363, 367-376.

Jayadev, A. (2008). A Power Law Tail in India's Wealth Distribution: Evidence from Survey Data. Physica A, 387, $270-276$.

Jiang, Z.-Q., Zhou, W.-X., Sornette, D., Woodard, R., Bastiaensen, K. \& Cauwels, P. (In press). Bubble Diagnosis and Prediction of the 2005-2007 and 2008-2009 Chinese Stock Market Bubbles. Journal of Economic Behavior and Organization.

Johansen, A. \& Sornette, D. (1998). Stock Market Crashes are Outliers. European Physical Journal B, 1, 141-143.

Kang, S. H. \& Yoon, S.-M. (2007). Long Memory Properties in Return and Volatility: Evidence from the Korean Stock Market. Physica A, 385, 591-600.

Kauffman, S. A. (1993). The Origins of Order. New York: Oxford University Press.

Kauffman, W. (2008). Shattering the Glass-Steagall Act. CounterPunch (Sept. 19, 2008) http://www.counterpunch.org/kaufman09192008.html (accessed Oct. 25, 2009). 
Kaufmann, D. (2008). Capture and the Financial Crisis: An Elephant Forcing a Rethink of Corruption? Blogs.worldbank.org, http://blogs.worldbank.org/governance/capture-and-the-financial-crisis-an-elephant-forcing-arethink-of-corruption (accessed Feb. 15, 2010).

Keene, S. (No date). Political economy: Evolutionary economics, power laws \& evolutionary modeling. Lecture slides; School of Economics \& Finance, University of Western Sydney. http://65.254.77.137/Old/Lectures/PolEcon/Week11PowerLawsModelling.pdf

Kennedy, P. (2003). A Guide to Econometrics (5th ed.). Cambridge, MA: MIT Press.

Knight, F. H. (1921). Risk, Uncertainty, and Profit. Boston: Houghton Mifflin.

Krugman, P. (2009). The Return of Depression Economics and the Crisis of 2008. New York: Norton \& Co.

Kumar, S. \& Deo, N. (2009). Multifractal Properties of the Indian Financial Market. Physica A, 388, 1593-1602.

Labaton, S. (2008). S.E.C. Concedes Oversight Flaws Fueled Collapse. New York Times (Sept. 26), http://www.nytimes.com/2008/09/27/business/27sec.html (accessed Feb. 15, 2010).

Labaton, S. (2009). Fed Plans to Vet Banker Pay to Discourage Risky Practices. New York Times (Oct. 23), http://www.nytimes.com/2009/10/23/business/23pay.html? rr=1 (accessed Feb. 15, 2010).

Lackritz, M. (2010). Separating Investment Banks Will Not Make Us Safer. Financial Times (Jan. 14), http://www.ft.com/cms/s/0/c88a0ec6-0141-11df-8c54-00144feabdc0.html (accessed Feb. 15, 2010).

Lahart, J. (2007). In Time of Tumult, Obscure Economist Gains Currency. Wall Street Journal (August 18); http://online.wsj.com/article/SB118736585456901047.html.

Lawson 2009. Capitalism Needs a Revived Glass-Steagall. Financial Times (March 16) http://www.ft.com/cms/s/0/9a8f3b22-1191-11de-87b1-0000779fd2ac.html?nclick_check=1 (accessed Oct. 25, 2009).

Leamer, E. E. (1990). In Hendry, D. F., Leamer, E. E. \& Poirier, D. J. (Eds.), A Conversation on Econometric Methodology. Econometric Theory, 6, 171-261

LeBaron, B. (2001). Volatility Magnification and Persistence in an Agent-based Financial Market. Working paper, Brandeis University, Boston, MA.

Lee, Y., Amaral, L. A. N., Canning, D., Meyer, M. \& Stanley, H. E. (1998). Universal features in the growth dynamics of complex organizations. Physical Review Letters, 81, 3275-3278.

Levy, M. \& Solomon, S. (1997). New Evidence for the Power-law Distribution of Wealth. Physica A, 242, 90-94.

Lintner, J. (1965). The Valuation of Risk Assets and the Selection of Risky Investments in Stock Portfolios and Capital Budgets. Review of Economics and Statistics, 47, 13-37.

Lowenstein, R. (2000). When Genius Failed: The Rise and Fall of Long-Term Capital Management. New York: Random House.

Mandelbrot, B. B. \& Hudson, R. L. (2004). The (mis)Behavior of Markets: A Fractal View of Risk, Ruin, and Reward. New York: Basic Books.

Mandelbrot, B. B. (1963a). The Variation of Certain Speculative Prices. Journal of Business, 36, 394-419.

Mandelbrot, B. B. (1963b). New methods in statistical economics. J. Political Econ. 71, 421-440.

Mandelbrot, B. B. (1982). The Fractal Geometry of Nature. New York: Freeman.

Mandelbrot, B. B. (1997). Fractals and Scaling in Finance, Discontinuity, Concentration, Risk. New York: SpringerVerlag.

Mantegna, R. N. (1991). Lévy Walks and Enhanced Diffusion in Milan Stock Exchange. Physica A, 179, 232-242.

Mantegna, R. N. \& Stanley, H. E. (2000). An Introduction to Econophysics: Correlations and Complexity in Finance. Cambridge, UK: Cambridge University Press.

Maskawa, J. (2007). Stock Price Fluctuations and the Mimetic Behaviors of Traders. Physica A, 382, 172-178. 
McCormack, R. (2009). A tax on short-term debt would stabilise the system. Financial Times, (Dec. 16): 13. http://www.ft.com/cms/s/0/0bf7a7d8-ea7a-11de-a9f5-00144feab49a.html (accessed Jan. 15, 2010).

McKelvey, B. (2010). Fixing the UK's Economy. In J. McGlade, M. Strathern \& K. Richardson (Eds.), Complexity in Human and Natural Systems. Litchfield Part, AZ: ISCE Publishing.

McKelvey, B., Lichtenstein, B. B. \& Andriani, P. (2010). When Systems and Ecosystems Collide: Is there a Law of Requisite Fractality Imposing on Firms?” In M. J. Lopez Moreno (Ed.), Chaos and Complexity in Organizations and Society. Madrid, Spain: UNESA.

Miller, J. \& Page, S. (2007). Complex Adaptive Systems: An Introduction to Computational Models of Social Life. Princeton, NJ: Princeton University Press.

Minsky, H. P. (1982). Can "It” Happen Again? Armonk, NY: M. E. Sharpe, Inc.

Minsky, H. P. (1986). Stabilizing an Unstable Economy. New Haven, CT: Yale University Press. $\left[2^{\text {nd }}\right.$ ed. published by McGraw-Hill, 2008.]

Mirowski, P. (1989). More Heat than Light. New York: Cambridge University Press.

Mishkin, F. (2009). Not all bubbles present a risk to the economy. Financial Times, (Nov. 10): p. 11.

Morris, C. R. (2008). The Two Trillion Dollar Meltdown (revised \& updated). New York: PublicAffairs.

Mu, G.-H. \& Zhou, W.-X. (2008). Relaxation Dynamics of Aftershocks after Large Volatility Shocks in the SSEC Index. Physica A, 387, 5211-5218.

Muzy, J.-F., Sornette, D., Delour, J. \& Arneodo, A. (2001). Multifractal Returns and Hierarchical Portfolio Theory, Quantitative Finance, 1, 131-148.

Nelson, D. B. (1991). Conditional Heteroskedasticity in Asset Returns: A New Approach. Econometria, 59, 347370.

Newman, M. E. J. (2005). Power Laws, Pareto Distributions and Zipf's Law. Contemporary Physics 46, 323-351.

Newman, M. E. J, Barabási, A.-L. \& Watts, D. J. (Eds.) (2006). The Structure and Dynamics of Networks. Princeton, NJ: Princeton University Press.

Nicolis, G. \& Prigogine. I. (1989). Exploring Complexity: An Introduction. New York: Freeman.

Odling-Smee, F. J., Laland, K. N. \& Feldman, M. W. (2003). Niche Construction. Princeton, NJ: Princeton U. Press.

Ormerod, P. \& Mounfield, C. (2001). Power law distribution of the duration and magnitude of recessions in capitalist economies breakdown of scaling. Physica A, 293, 573-582.

Pareto, V. (1897). Cours d"Economie Politique. Paris: Rouge \& Cie.

Pariès, J. (2006). Complexity, emergence, resilience.... In Hollnagel, E., D. D. Woods, \& N. Leveson (Eds.), Resilience Engineering: Concepts and Precepts, pp. 43-53. Aldershot, Hampshire, UK: Ashgate.

Patriarca, M., Chakraborti, A. \& Germano, G. (2006). Influence of Saving Propensity on the Power-law Tail of the Wealth Distribution. Physica A, 369, 723-736.

Phillips, K. (2008). Bad Money. New York: Viking, Penguin Group.

Plerou, V., Amaral, L.A.N., Gopakrishnan, P., Meyer, M. \& Stanley, H. E. (1999). Similarities between the Growth Dynamics of University Research and Competitive Economic Activities. Nature, 400, 433-437.

Plerou, V., Gopikrishnan, P. \& Stanley, H. E. (2003). Two-phase behaviour of financial markets. Nature, 421, 130.

Podobnik, B., Fu, D., Jagric, T., Grosse, I. \& Stanley, H. E. (2006). Fractionally Integrated Process for Transition Economics. Physica A, 362, 465-70.

Poincaré, H. (1914). Science and Method (tran. Francis Maitland). London: T. Nelson. [Originally Science et Méthode, 1908].

Poon, S.-H. \& Granger, C. W. J. (2003). Forecasting volatility in financial markets: A review. Journal of Economic Literature, 41, 478-539. 
Pozen, R. (2010). A Mistake that Will Make Banks Riskier. Financial Times (Jan. 12) http://www.ft.com/cms/s/0/06cfecac-fecf-11de-91d7-00144feab49a.html (accessed Feb. 15, 2010).

Prigogine, I. (1955). An Introduction to Thermodynamics of Irreversible Processes. Springfield, IL: Thomas.

Prigogine, I. \& Stengers, I. (1984). Order Out of Chaos: Man's New Dialogue with Nature. New York: Bantam.

Ravasz, E. \& Barabási, A.-L. (2003). Hierarchical Organization in Complex Networks. Physical Review E, 67, 026112-1-7.

Record, N. (2010). How to Make the Bankers Share the Losses. Financial Times (Jan 6) http://www.ft.com/cms/s/0/dda17cc4-fafa-11de-94d8-00144feab49a.html (accessed Feb. 15, 2010).

Redelico, F. O., Proto, A. N. \& Ausloos, M. (2008). Power law for the duration of recession and prosperity in Latin American countries. Physica A, 387, 6330-6336.

Rogoff, C. M. \& Rogoff, K. S. (2009). This Time Is Different: Eight Centuries of Financial Folly. Princeton, NJ: Princeton University Press.

Rook, L. (2006). An Economic Psychological Approach to Herd Behavior. Journal of Economic Issues, 40, 75-95.

Rosser, J. B., Jr. (2008). Econophysics. In L. E. Blume \& S. N. Durlauf (Eds.), The New Palgrave Dictionary of Economics, (2nd ed). New York: Palgrave Macmillan

Rosser, J. B., Jr. (1994). Dynamics of Emergent Urban Hierarchy. Chaos, Solitons \& Fractals, 4, 553-562.

Rostowski, J. (2010). Intolerance of Small Crises Led to this Big One. Financial Times (January 14), http://www.ft.com/cms/s/0/602fd6ee-0079-11df-b50b-00144feabdc0.html (accessed Feb. 15, 2010).

Samuelson, P. A. (1947). Foundations of Economic Analysis. Cambridge, MA: Harvard University Press.

Sanchez Gránero, M. A., Trinidada Segovia, J. E. \& García Peréz, J. (2008). Some Comments on Hurst Exponent and the Long Memory Processes on Capital Markets. Physica A, 387, 5543-5551.

Sanderson, R. \& Hughes, J. (2009). Banks face change to loan losses rule. Financial Times, (Nov. 6): 15.

Santiago, A. \& Benito, R. M. (2008). Connectivity Degrees in the Threshold Preferential Attachment Model. Physica A, 387, 2365-2376.

Schroeder, M. (1991). Fractals, Chaos, Power Laws. New York: Freeman \& Co.

Selise (2009). Which Idiot Decided to Repeal Glass-Steagall? http://seminal.firedoglake.com/diary/3828 (accessed Oct. 25, 2009).

Sethi, R. (1996). Endogenous regime switching in speculative markets. Structural Change and Economic Dynamics, 7, 99-118.

Shackle, G. L. S. (1949), Expectations in Economics. Cambridge: Cambridge University Press.

Sharp, W. F. (1964). Capital Asset Prices: A Theory of Market Equilibrium Under Conditions of Risk. Journal of Finance, 19, 425-442.

Sheehan (2008). Larry Summers Repealed the Glass-Steagall Act so Citicorp could become Citigroup. http://obambi.wordpress.com/2008/11/24/larry-summers-repealed-the-glass-steagall-act-so-citicorp-couldbecome-citigroup/ (accessed Oct. 25, 2009).

Sinha, S. (2006). Evidence for Power-law Tail of the Wealth Distribution in India. Physica A, 395, 555-562.

Sorkin, A. R. (2009). Too Big to Fail. New York: Viking Penguin.

Song, D.-M., Jiang, Z.-Q. \& Zhou, W.-X. (2009). Statistical Properties of World Investment Networks. Physica A, $388,2450-2460$.

Sornette, D. \& Johansen, A. \& Bouchaud, J.-P. (1996). Stock Market Crashes, Precursors and Replicas. Journal Phys. I France, 6, 167-175.

Sornette, D. \& Johansen, A. (2001). Significance of Log-periodic Precursors to Financial Crashes. Quantitative Finance, 1, 452-471. 
Sornette, D. \& Zajdenweber, D. (1999). Economic Returns of Research: The Pareto Law and its Implications. European Physical Journal B, 8, 653-664.

Sornette, D. \& Zhou, W.-X. (2006). Predictability of Large Future Changes in Major Financial Indices. International Journal of Forecasting, 22, 153-168.

Sornette, D. (2003a). Critical Market Crashes. Physics Reports, 378(11), 1-98, Elsevier Science.

Sornette, D. (2003b). Why Stock Markets Crash? Princeton, NJ: Princeton University Press.

Sornette, D. \& Woodard, R. (2009). Financial bubbles, real estate bubbles, derivative bubbles, and the financial and economic crisis. Submitted to Quantitative Finance. http://arXiv.org/abs/0905.0220 (accessed Nov. 15, 2009).

Sornette, D., Deschatres, F., Gilbert, T. \& Ageon, Y. (2004). Endogenous versus Exogenous Shocks in complex Networks: An Empirical Test Using Book Sale Rankings. Physical Review Letters, 93, 228701-1-4.

Sornette, D., Malevergne, Y. \& Muzy, J.-F. (2002). Volatility Fingerprints of Large Shocks: Endogenous versus Exogenous. http://arXiv:cond-mat/0204626v1 [cond-mat.stat-mech] (accessed Oct. 22, 2009).

Soros, G. (2008). The New Paradigm for Financial Markets. New York: Public Affairs.

Souma, W., Aoyama, H., Fujiwara, Y., Ikeda, Y., Iyetomi, H. \& Kaizoji, T. (2006). Correlation in Business Networks. Physica A, 370, 151-155.

Spanos, A. (1986). Statistical Foundations of Econometric Modelling. Cambridge, UK: Cambridge University Press.

Stanley, H. E., L. A. N. Amaral, S. V. Buldyrev, P. Gopikrishnan, V. Plerou \& M. A. Salinger (2002). Selforganized Complexity in Economics and Finance. Proceedings of the National Academy of Sciences, 99(Suppl. 1), 2561-2565

Stanley, M. H. R., Amaral, L. A. N., Buldyrev, S. V., Havlin, S., Leschhorn, H., Maass, P., Salinger, M. A. \& Stanley, H. E. (1996). Scaling Behavior in the Growth of Companies. Nature, 379, 804-806.

Stanley, M. H. R., Amaral, L. A. N., Gopikrishnan, P. \& Plerou, V. (2000). Scale invariance and universality of economic fluctuations. Physica A, 283, 31-41.

Stanley, H. E., Plerou, V. \& Gabaix, X. (2008). A Statistical Physics View of Financial Fluctuations: Evidence for Scaling and Universality. Physica A, 387, 3967-3981.

Struzik, Z. (2001). Wavelet Methods in (Financial) Time-series Processing. Physica A, 296, 307-319.

Summers, L. (1991). Scandinavian Journal of Econometrics, 93, 129-148)

Takayasu, H. \& Okuyama, K. (1998). Country Dependence on Company Size Distributions and a Numerical Model Based on Competition and Cooperation. Fractals, 6, 67-79.

Task, A. (2010). Kill Wall Street Bonuses or Tax “em to Death, MIT’s Simon Johnson Says. Yahoo! Finance (Jan. 12), http://finance.yahoo.com/tech-ticker/kill-wall-street-bonuses-or-tax-\%27em-to-death-mit\%27s-simonjohnson-says-402210.html?tickers=XLF,JPM,GS,BAC,C,MS,WFC (accessed Feb. 15, 2010).

The Economist (2009a). Efficiency and Beyond. Vol. 392(8640; July 18): 71-72).

The Economist (2009b). The Other-worldly Philosophers. Vol. 392(8640; Nov. 26): 68-70.

The Economist (2009c). Too Big to Bail Out. Vol. 393(8654; Oct. 24): 68.

The Economist (2010). A Special Report on Financial Risk. Vol. 394(8669; Feb. 13): 18 pages after p. 52.

Thomas, L. (2010). British Central Banker Favors Splitting Big Banks. New York Times (Jan. 27), http://dealbook.blogs.nytimes.com/2010/01/27/british-central-banker-favors-splitting-bigbanks/?scp=1\&sq=Landon\%20thomas\%20British\&st=cse (accessed Feb. 15, 2010).

Turner, J. S. (2000). The Extended Organism. Cambridge, MA: Harvard University Press.

Vasconcelos, G. L. (2004). A Guided Walk Down Wall Street: An Introduction to Econophysics. Brazilian Journal of Physics, 34, 1039-1065.

Wasden, C. L. (2010). Taxonomy of Social Tensions Derived from the Global Financial Crisis: An Exploratory 
Sequential Partial Mixed methods Study. PhD Dissertation, Graduate School of Education and Human Development, George Washington University, Washington, DC.

Watts, D. (2003). Six Degrees: The Science of a Connected Age. New York: Norton.

Wei, Y. \& Wang, P. (2008). Forecasting Volatility of SSEC in Chinese Stock Market Using Multifractal Analysis. Physica A, 387, 1585-1592.

West, B. J. \& Deering, B. (1995). The Lure of Modern Science: Fractal Thinking. Singapore: World Scientific.

Westrum, R. (2006). A typology of resilience situations. In Hollnagel, E., D. D. Woods, \& N. Leveson (Eds.), Resilience Engineering: Concepts and Precepts, pp. 55-65. Aldershot, Hampshire, UK: Ashgate.

Wolfson, M. H. (2002). Minsky's Theory of Financial Crises in a Global Context. Journal of Economic Issues, 36, 393-400.

Wong, J. C., Lian, H. \& Cheong, S. A. (2009). Detecting Macroeconomic Phases in the Dow Jones Industrial Average Time Series. Physica A, 388, 4635-4645.

Woods, D. D., \& E. Hollnagel (2006). Prologue: Resilience engineering concepts. In Hollnagel, E., D. D. Woods, \& N. Leveson (Eds.), Resilience Engineering: Concepts and Precepts, pp. 1-6. Aldershot, Hampshire, UK: Ashgate.

Yakovenko, V. M. \& Rosser, J. B. Jr. (2009). Colloquium: Statistical Mechanics of Money, Wealth, and Income. Review of Modern Physics, 81, 1703-1725.

Yalamova, R. (2003). Wavelet MRA of Index Patterns around Stock Market Shocks. PhD dissertation, Kent State University.

Yalamova, R. (2010). Stock Market Index Dynamics before Crashes: A Time-scale Adaptive Research Framework. Working paper, Faculty of Management, University of Lethbridge, Canada.

Yalamova, R., \& B. McKelvey (2009). Explaining what leads up to stock market crashes: A phase transition model and scalability dynamics. Working paper, University of Lethbridge, Canada.

Yan, W., Woodard, R. \& Sornette, D. (2010). Diagnosis and Prediction of Tipping Points in Financial Markets: Crashes and Rebounds. Physics Procedia, 00,1-17.

Yergin, D. (2009). A Crisis in Search of a Narrative. Financial Times (Oct. 20). http://www.ft.com/cms/s/0/8a82d274-bda9-11de-9f6a-00144feab49a.html (accessed Oct. 24, 2009).

Zanini, M. (2008). Using “Power Curves” to Assess Industry Dynamics. McKinsey Quarterly (Nov.) 1-6.

Zhang, F. (2006). Information Uncertainty and Stock Returns, Journal of Finance, 61, 105-37.

Zhang, J., Chen, Z. \& Wang, Y. (2009). Zipf Distribution in Top Chinese Firms and an Economic Explanation. Physica A, 388, 2020-2024.

Zhou, W.-X. \& Sornette, D. (2002). Generalized q-analysis of Log-periodicity: Application to Critical Ruptures. Physical Review E, 66(4), 129-136.

Zhou, W.-X. \& Sornette, D. (2003). Non-parametric Analysis of Log-periodic Precursors to Financial Crashes. International Journal of Modern Physics C, 14, 1107-1126.

Zipf, G. K. (1935). The Psychobiology of Language. Boston, MA: Houghton-Mifflin.

Zipf, G. K. (1941). National Unity and Disunity. Bloomington, IN: Principia Press.

Zipf, G. K. (1949). Human Behavior and the Principle of Least Effort. New York: Hafner.

Zunino, L., Zanin, M., Tabak, B. M., Pérez, D. G. \& Rosso, O. A. (2009). Forbidden Patterns, Permutation Entropy and Stock Market Inefficiency. Physica A, 388, 2854-2864. 
Figure 1: Financial Markets Phase Diagram

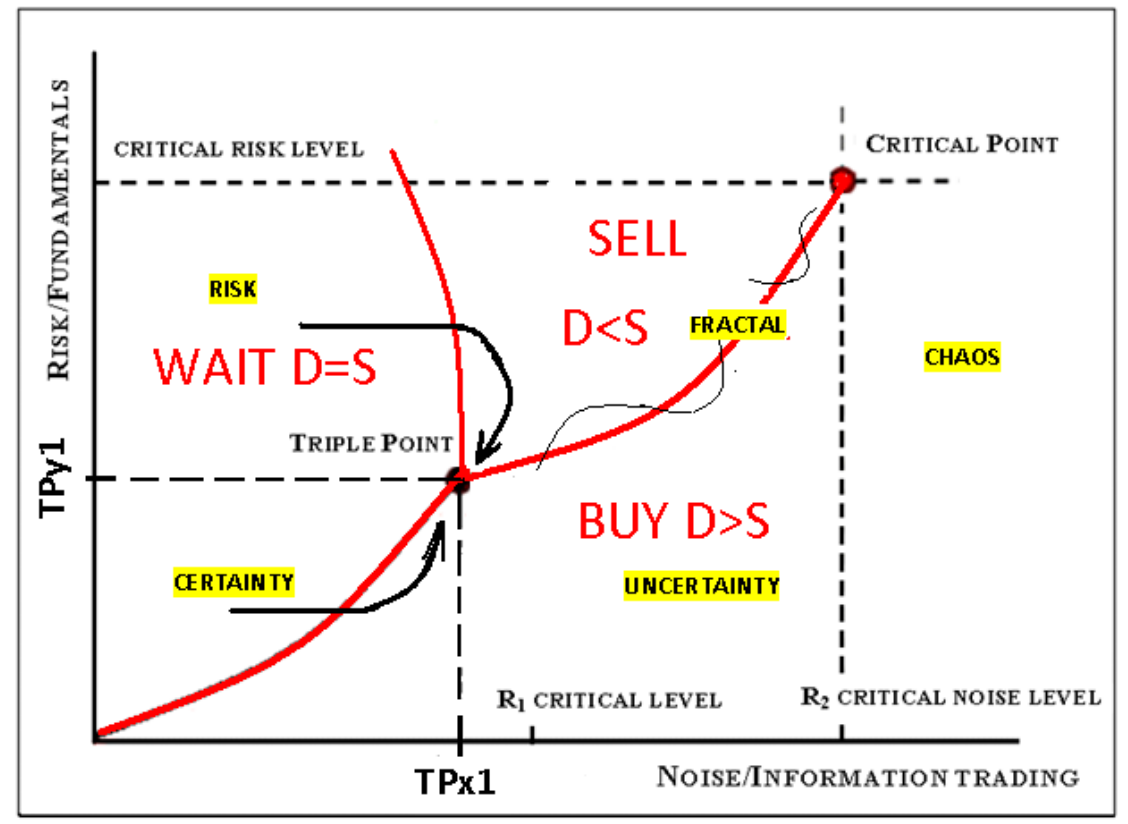

Reproduced from Yalamova and McKelvey (2010)

Figure 2: Depiction of Volatility Incidents Above the GARCH Line*

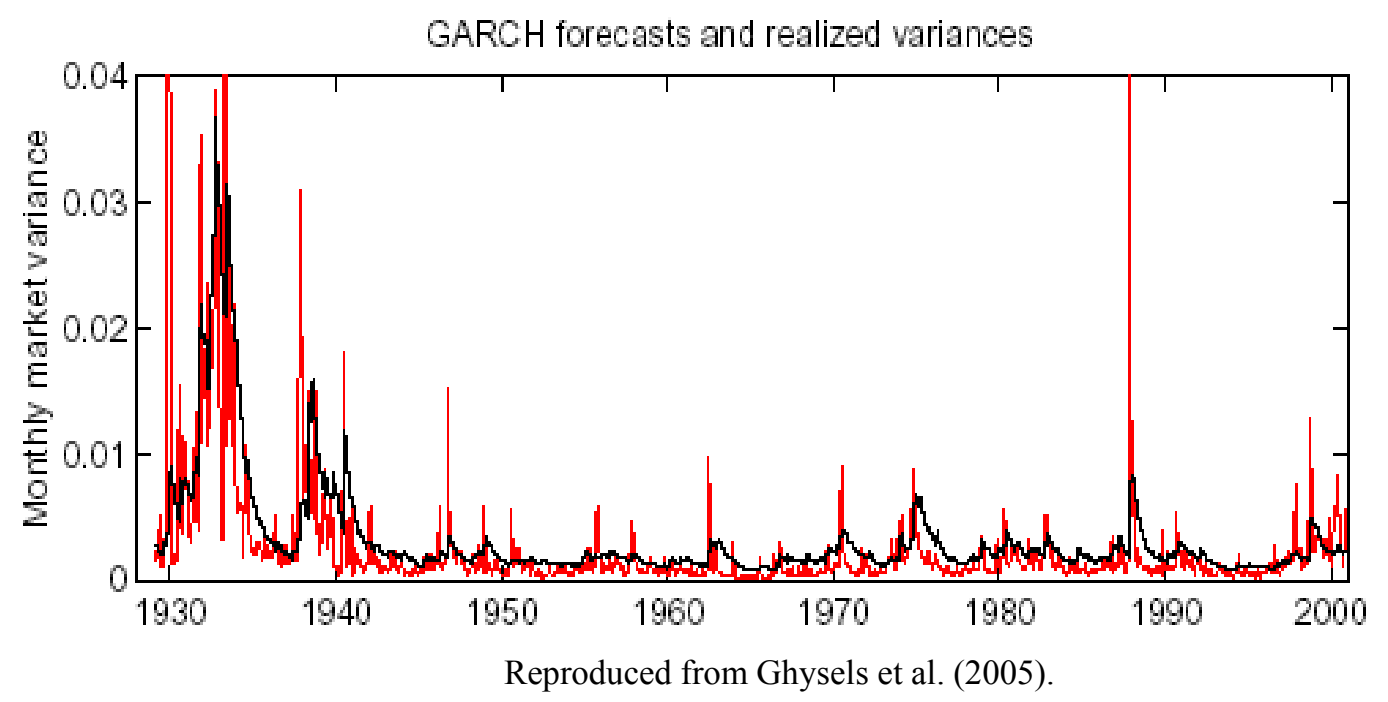


Figure 3: Power-Law Fit DJIA (\# events vs. \% daily change)

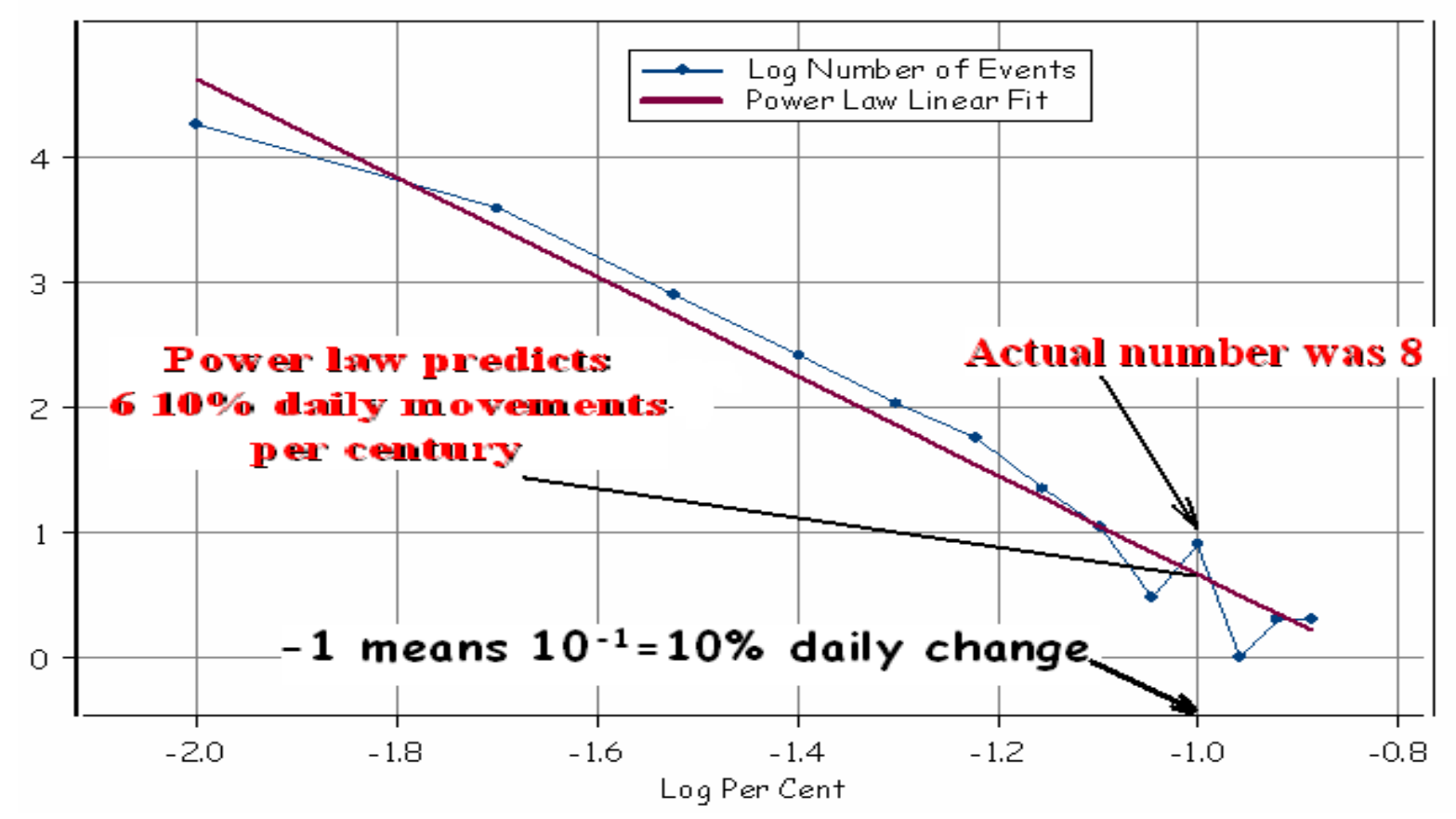

Reproduced from Keen (No date).

Figure 4: DJIA Daily Returns 1928-2007

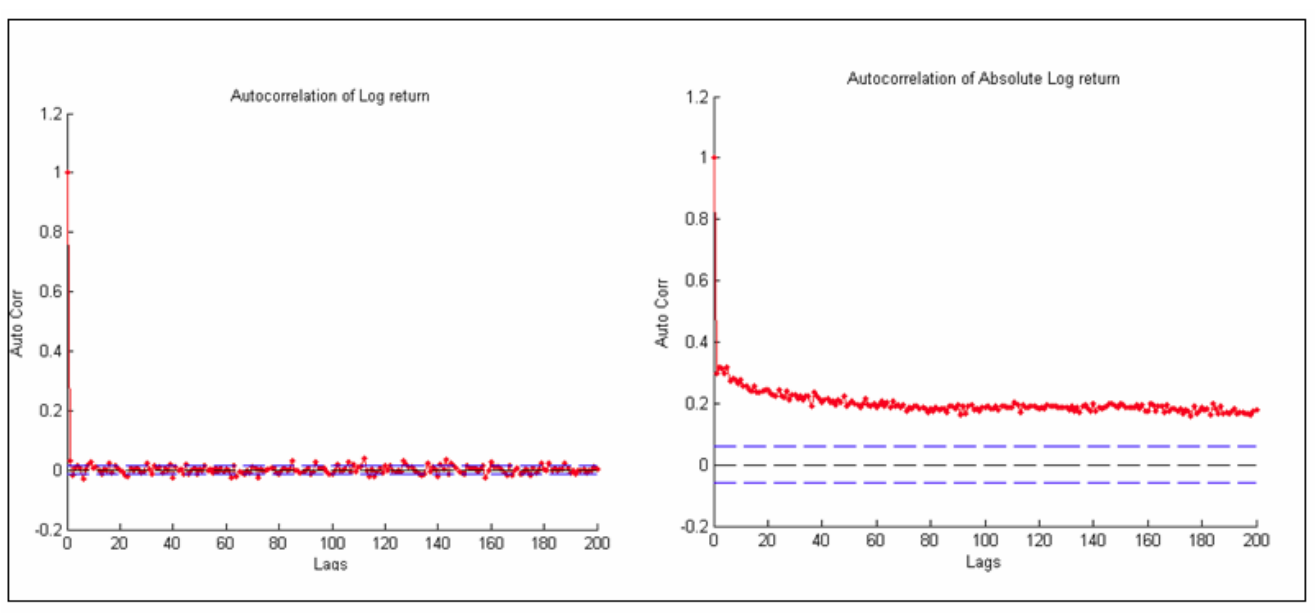

Reproduced from Yalamova et al. (2007: page) 
Figure 5: Power Spectrum of DJIA Price levels with Wavelets
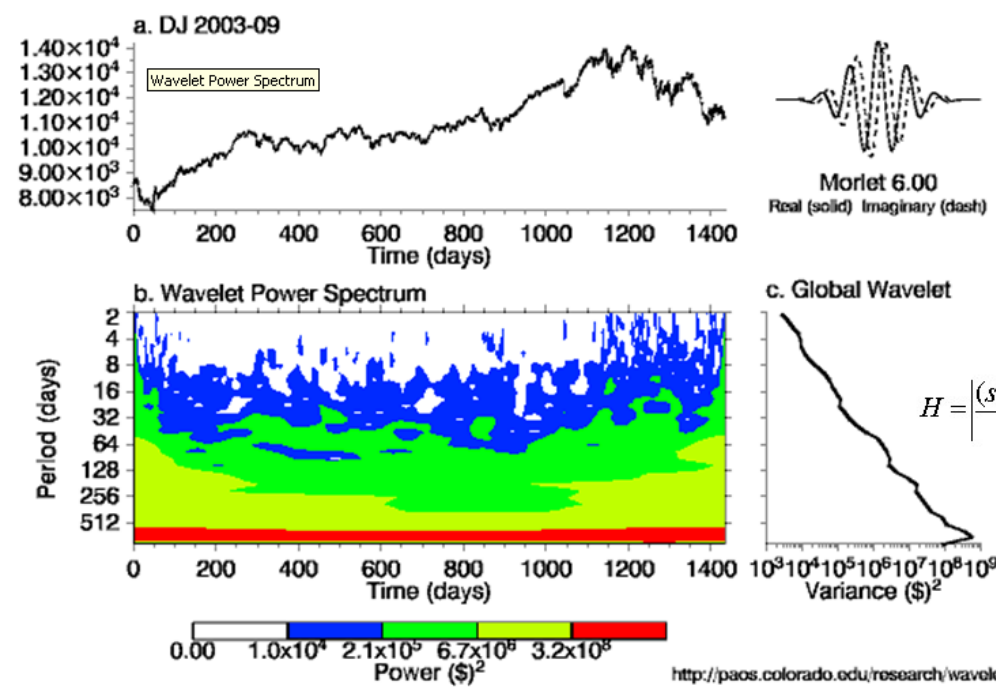

c. Global Wavelet

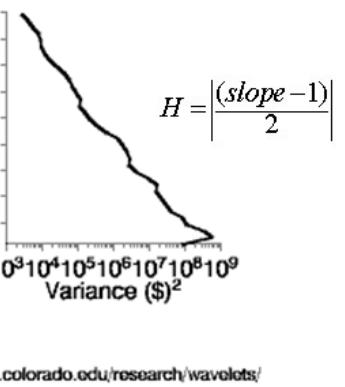

Fig. 1: (a) DJ 2003-09. (b) The wavelet power spectrum. The contour levels are chosen so that $75 \%$, $50 \%, 25 \%$, and $5 \%$ of the wavelet power is above each level, respectively. (c) The global wavelet power spectrum. Reference: Torrence, C. and G. P. Compo, 1998: A Practical Guide to Wavelet Analysis. Bull. Amer. Meteor. Soc. 79, 61-78. 
Figure 6: Hang-Seng Market translated from Linear to log-scale Y-Axis*

\author{
QuickTime $^{\mathrm{TM}}$ and a \\ TIFF (LZW) decompressor \\ are needed to see this picture.
}

Reproduced from Sornette \& Johansen (2001) 
Figure 7: Log-periodicity in the Hang-Seng Stock Market (1970-2000)*

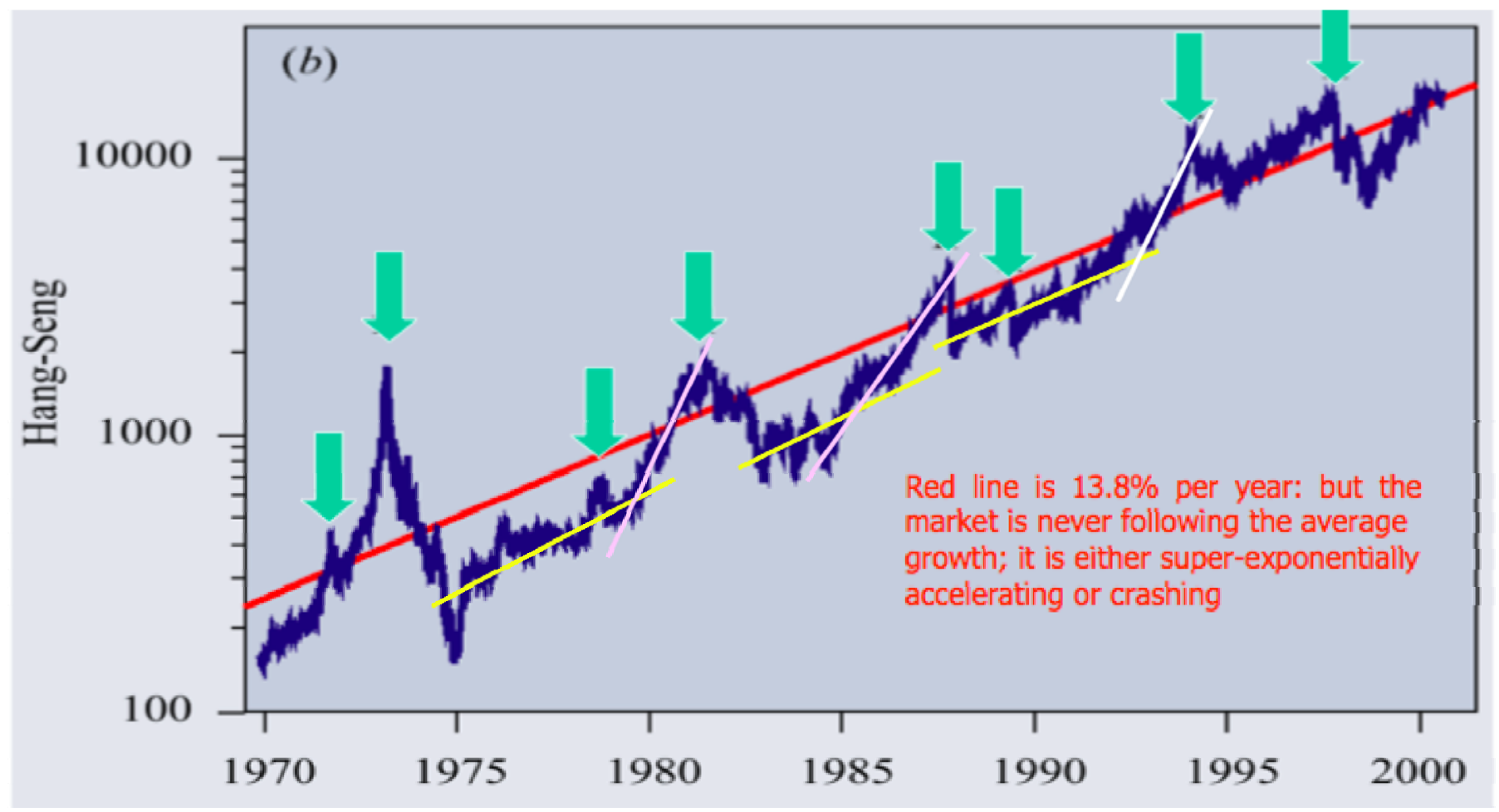

*Reproduced from Sornette \& Woodard (2009) 
TABLE 1: SCALE-FREE THEORIES DEFINED AND CONNECTED TO 2007 CRISIS BUILD-UP

\begin{tabular}{|c|c|c|}
\hline SFTs & Scale-free Theories Defined & TRADER-BASED SCALE-FREE EXAMPLES \\
\hline $\begin{array}{l}\text { Phase } \\
\text { transition }\end{array}$ & $\begin{array}{l}\text { Turbulent flows: Exogenous energy impositions cause } \\
\text { autocatalytic, interaction effects and percolation } \\
\text { transitions at a specific energy level-the } 1^{\text {st }} \text { critical } \\
\text { value-such that new interaction groupings form with } \\
\text { a Pareto distribution (Prigogine, 1955; Nicolis \& } \\
\text { Prigogine, 1989). }\end{array}$ & $\begin{array}{l}\text { 1973: } 1^{\text {st }} \text { critical value threshold lowered; use of derivatives } \\
\text { lowers the } 1^{\text {st }} \text { critical value threshold such that high-risk \& } \\
\text { high-leverage investment practices emerge with less initial } \\
\text { risk. } \\
\text { 1979: } 1^{\text {st }} \text { critical value threshold lowered (computers } \\
\text { become cheaper; "quants" move into Finance); emergent } \\
\text { degrees of freedom in re-combinations of high-risk tranches } \\
\text { are obscured by the complexity of the securitization } \\
\text { packages. } \\
\text { 1986: Securitization packages lowered the risk threshold for } \\
\text { taking advantage of mortgage-backs; what emerged was a } \\
\text { complex obscuritization of mortgage-backed risk } \\
\text { vulnerabilities. } \\
\text { 2000: } 1^{\text {st }} \text { critical value threshold lowered; fosters emergent } \\
\text { low-interested based mortgage policies. }\end{array}$ \\
\hline $\begin{array}{l}\text { Contagion } \\
\text { bursts }\end{array}$ & $\begin{array}{l}\text { Epidemics; idea contagion: Often, viruses are spread } \\
\text { exponentially-each person coughs upon two others } \\
\text { and the network expands geometrically. But, changing } \\
\text { rates of contagious flow of viruses, stories, and } \\
\text { metaphors, because of changing settings such as almost } \\
\text { empty or very crowded rooms and airplanes, result in } \\
\text { bursts of contagion or spreading via increased } \\
\text { interactions; these avalanches result in the power-law } \\
\text { signature (Watts, 2003; Baskin, 2005) due to the small- } \\
\text { world structures of the underlying networks. }\end{array}$ & $\begin{array}{l}\text { 1973: Banks substitute for crowded rooms, buses, and } \\
\text { planes, thereby spreading contagion more quickly. } \\
\text { 2000: Banks stop asking for credit \& income statements; } \\
\text { borrowers learn about cheap mortgages; towns and builders } \\
\text { learn to build housing developments to take advantage; real } \\
\text { estate agents start speculative buying, reselling. } \\
\text { 2002: Agents connected to banks speeds up the spread of } \\
\text { the teaser loan idea. } \\
\text { 2006: Now fueling rapid decline rather than rapid growth. }\end{array}$ \\
\hline $\begin{array}{l}\text { Preferential } \\
\text { attachment }\end{array}$ & $\begin{array}{l}\text { Nodes; gravitational attraction: Given newly arriving } \\
\text { agents into a system, larger nodes with an enhanced } \\
\text { propensity to attract agents will become } \\
\text { disproportionately even larger, resulting in the power } \\
\text { law signature (Barabási, 2002; Newman, 2005). }\end{array}$ & $\begin{array}{l}\text { 2002: Some banks (e.g., Countrywide, IndyMac, WaMu, } \\
\text { Freddy Mac, Fanny Mae, etc.), became especially well } \\
\text { known for offering teaser loans with few questions asked; } \\
\text { they then had links to other banks (which were often later } \\
\text { acquired). } \\
\text { 2006: In reverse; i.e., the networks and attachments now } \\
\text { spread panic and decline. }\end{array}$ \\
\hline $\begin{array}{l}\text { Irregularity } \\
\text { generated } \\
\text { gradients }\end{array}$ & $\begin{array}{l}\text { Coral growth; blockages: Starting with a random, } \\
\text { insignificant irregularity, coupled with positive } \\
\text { feedback, the initial irregularity starts an autocatalytic } \\
\text { process driven by emergent energy gradients, which } \\
\text { results in the emergence of a niche. This explains the } \\
\text { growth of coral reefs, innovation systems (Turner, } \\
\text { 2000, Odling-Smee et al., 2003). }\end{array}$ & $\begin{array}{l}\text { 1979: Individually insignificant innovations plus positive } \\
\text { feedback fuel rapid, unwatched, and unchecked growth. } \\
\text { 1999: Contagion is bank by bank as opposed to random } \\
\text { individuals; speeds up gross risk-taking by banks. }\end{array}$ \\
\hline $\begin{array}{l}\text { Spontaneous } \\
\text { order } \\
\text { creation }\end{array}$ & $\begin{array}{l}\text { Heterogeneous agents seeking out other agents to } \\
\text { copy/learn from so as to improve fitness generate } \\
\text { networks; there is some probability of positive } \\
\text { feedback such that some networks become groups, } \\
\text { some groups form larger groups \& hierarchies } \\
\text { (Kauffman, 1993; Holland, 1995). }\end{array}$ & $\begin{array}{l}\text { 1979: Banks, as agents, communicate, learn, influence each } \\
\text { other with positive feedback effects. } \\
\text { 2000: People learn to use cheap money to refinance their } \\
\text { houses; often several times; mortgages increase in value; } \\
\text { debt-based spending increases; fragility of the economy } \\
\text { increases. }\end{array}$ \\
\hline $\begin{array}{l}\text { Combination } \\
\text { theory }\end{array}$ & $\begin{array}{l}\text { Number of exponentials; complexity: Multiple } \\
\text { exponential or lognormal distributions or increased } \\
\text { complexity of components subtasks, processes) sets up, } \\
\text { which results in a power law distribution (West \& } \\
\text { Deering, 1995; Newman 2005). }\end{array}$ & $\begin{array}{l}\text { 1986: Increased complexity of securitization packaging } \\
\text { results in combinations of high-default-risk tranches that } \\
\text { compound into securitization packages more likely to show } \\
\text { skew distributions; \& Pareto extremes. } \\
\text { 2003: Increased complexity of securitization packaging with } \\
\text { increasing leverage results in combinations of skew } \\
\text { distributions that compound into Pareto extremes and the } \\
\text { ultimate panic and collapse of bank liquidity. }\end{array}$ \\
\hline
\end{tabular}

